

\title{
PUBLIC OPINION ABOUT INTERNATIONAL TRADE: assessing the impact of cultural proximity
}

\author{
Dissertação apresentada ao Instituto de Relações \\ Internacionais da Universidade de São Paulo (IRI- \\ USP) para a obtenção do título de Mestre em \\ Ciências - Programa de Pós-Graduação em Relações \\ em Internacionais.
}

Linha de Pesquisa: Economia Política Internacional

Orientador: Prof. Dr. Amâncio Jorge Silva Nunes de Oliveira

Banca examinadora:

Orientador: Prof. Dr. Amâncio Jorge Silva Nunes de Oliveira (IRI-USP)

Prof $^{a}$. Dr ${ }^{\mathrm{a}}$. Janina Onuki (IRI-USP)

Prof. Matthew Winters (University of Illinois)

Este trabalho foi realizado com apoio do Programa Estudantes -Convênio de Pós-Graduação (PEC-PG) da CNPq/CAPES Brasil

São Paulo

2014 


\section{FICHA CATALOGRÁFICA}

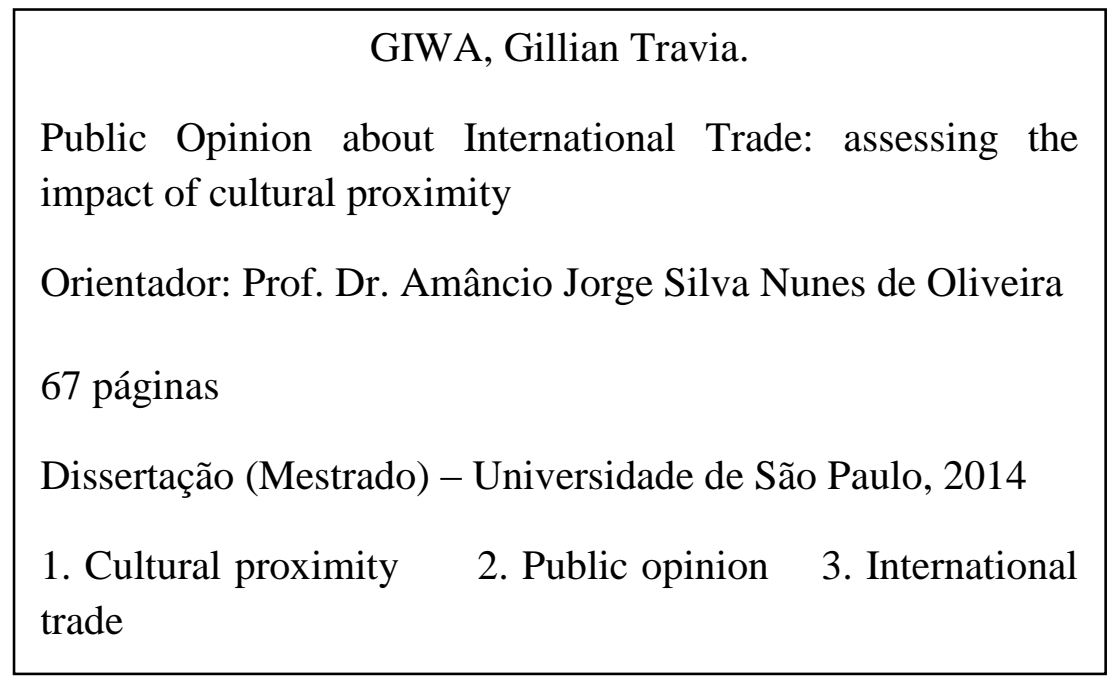


To Mom 


\section{Acknowledgments}

The proverb "one hand can't clap" reflects with accuracy my feeling of gratitude towards all who contributed to the completion of this research. While this thesis is a consolidation of 2 years of dedicated study I have received immeasurable assistance, support, advice and prayers for which I will be forever indebted. Those highlighted here are a mere fraction of the people who have made this trajectory possible, and the non-identification of others does not imply any less appreciation.

The government of Brazil via the National Council for Scientific and Technological Development $(\mathrm{CNPq})$ has facilitated my attaining this milestone through the PEC-PG scholarship programme. As a beneficiary of this scholarship both at the undergraduate and graduate levels I know firsthand what a privilege this has been and so I extend my heartfelt 'muitíssimo obrigrada'.

The Institute of International Relations (IRI/USP) has enriched this academic experience through its high standards of teaching, research and commitment to excellence. The thoughtfulness and efficiency of the professors and department staff made focusing on studies that more pleasurable.

Notwithstanding, my research home for the last 2 years has been the Centre for International Negotiation Studies (CAENI) and though the door was initially opened to me by my advisor Professor Amâncio Jorge Silva Nunes de Oliveira, the daily coexistence with the other professors and research fellows gave a renewed significance to that study space. The many workshops and seminars and constant intellectual stimulation are only a few of the memories that have been etched into my mind. Professor Janina, thank you for never being too busy for giving an ear and support to my interests in CAENI. Rafael, through our many conversations you served as a sounding board and a much appreciated help during the pilot stage of this research. Thank you.

The guidance, patience and support of my advisor during this period have been inestimable. Professor Amâncio, you not only provided the institutionally required orientation I needed, but forced me out of my 'qualitative' comfort zone, introduced me to the world of survey experiments and backed my pursuit of a this research agenda even when the odds looked dim and better judgment would probably have suggested otherwise.

Professor Matthew Winters, you have undoubtedly been my guardian angel throughout this process. Your numerous reviews and valuable feedback from the project stage all the way through to the pilot and execution of the survey experiment were priceless and extremely appreciated.

To my friends who made sure I maintained an equal footing with social obligations (Rob, Matheus), to those with whom I shared many a 'bandejões' and random conversations, and to 
those whose home became my own (Maria Raimunda, Gabriela and Natália) my sincere thank you. You have all been essential to my successful completion of this task.

The encouragement of my family is something I have always been able to count on. Mom, your unending prayers, genuine interest and constant pushing me on to achieve my goals have not gone unnoticed, and I dedicate this accomplishment to you.

Ashley, La-Shauna and Zee thanks for the many hours spent teleconferencing. The distance was shortened by those conversations and they truly made the process easier to handle. Though infrequent conversations are the trademark of my paternal family you have been no less supportive of my achievements, and for that I am grateful.

The acknowledgment of my support system would not be complete however without mentioning a few of my 'invisible heroes' - Sir N and the Collashes, whose dedication to my spiritual wellbeing has been paramount to my success.

In closing, I adopt a quote from Booker T. Washington that I consider appropriate for this occasion:

I believe that any man's life will be filled with constant, unexpected encouragements of this kind if he makes up his mind to do his level best each day of his life - that is, tries to make each day reach as nearly as possible the high-water mark of pure, unselfish, useful living.

(extract from: Up from Slavery, an autobiography, Floating Press, 2009)

Muito obrigada!

Thank you! 


\section{Overview}

The general theory proposed in this thesis is that culture matters to public opinion. Within the context of policymaking, culture is argued as exerting a regulatory boundary on public preferences and specific to issue of trade it acts as a determining variable in the opinion-policy connection. Comprised of two papers, one theory oriented and the other derived from empirical data, this masters' thesis is intended to contribute to the strengthening of the opinion-trade research agenda.

The first paper, entitled, The Public Restrained: observing the regulatory boundaries of culture and democracy over public opinion establishes a theoretical premise for arguing culture's relevance to public preferences and opinions about trade related policy. This, based on the hypothesis that contextual nuances such as culture and democracy create regulatory boundaries that coerce public opinion, orient public preferences and regulate the participatory powers of the public. The literature suggests that while there may be a questionable causal dilemma between democracy and culture, the claim of a culture - opinion causal relationship is substantiated.

The second paper empirically examines how cultural (dis)similarity affects people's opinions about trade partners. This paper entitled, The Impact of Cultural Proximity on Public Opinion about Trade Partners: evidence from an experimental survey, recapitulates the procedures, protocol and results from a survey experiment administered among the undergraduate student's population from the University of São Paulo. While the choice of methodology calls attention to the value of experimental methods in International Relations (I.R.) research, the results corroborate the hypothesis that cultural proximity influences public preference for trade partners.

Culture's influencing capabilities in areas of economic development, trade and domestic policies has been long debated and yet continues to be an issue of contention. While it goes beyond the scope of this thesis to address all the concerns of the opinion-trade relationship, the findings about the impact of cultural proximity provide an additional resource for future studies in this field. 


\title{
The Public Restrained: observing the regulatory boundaries of culture and democracy over public opinion
}

\begin{abstract}
The interwoven relationship between domestic politics and international affairs continues to be a highly debated aspect of International Relations studies. The complexity and multidimensionality of the domestic arena is of particular interest in this paper, especially as with regards to the role and function of public opinion in the deliberative processes of policymaking. The hypothesis proposed in this paper is that contextual nuances such as culture and democracy create regulatory boundaries that coerce public opinion, orient public preferences and regulate the participatory powers of the public. To this end, culture and democracy are examined on the basis of their influence over public opinion and preference for trade related policies. Predominantly, a review of the opinion - policy literature, the paper begins with a reflection on democracy's evolutionary trajectory and its implications for public participation in government. A substantial discussion about culture's role as a determining factor in public opinion is subsequently presented and evidence from empirical, experimental as well as formal models of research validate the claim of a culture - opinion causal relationship. Talks of an inclusion of 'popular councils' into the Brazilian legislative process provide a timely backdrop for the arguments proposed in this paper. This, as it relates to the democratization of the policymaking process.
\end{abstract}

Keywords: culture, democracy, public opinion, policy preference.

Resumo: A relação entrelaçada entre a política doméstica e as internacionais continua a ser muito debatido nos estudos de Relações Internacionais. A complexidade e a multidimensionalidade da arena doméstica são os focos deste trabalho por enfatizar o papel e a função da opinião pública nos processos deliberativos de políticas públicas. Neste artigo, a hipótese é que nuanças contextuais, tais como a cultura e a democracia, criam limites regulatórios que coajem a opinião pública, orientam e regulam as preferências e as capacidades participatórios do público. Neste sentido, a cultura e a democracia são analisadas a partir de sua influência na opinião pública em relação às preferências por políticas comerciais. Na maior parte do artigo foi realizada a revisão da literatura que relaciona a opinião pública com as políticas públicas. $\mathrm{O}$ artigo começa com a reflexão acerca da trajetória evolutiva da democracia e suas implicações para a participação pública no governo. Em seguida, discute-se substancialmente o papel da cultura como um fator determinante para a opinião pública. Evidências derivadas de modelos formais, empíricos e experimentais validam a hipótese da relação causal entre cultura e opinião pública. A proposta da inclusão de "conselhos populares" no processo legislativo brasileiro favorece um contexto oportuno para discutir os argumentos apresentados neste trabalho, principalmente no que tange a democratização da formulação de políticas.

Palavras chaves: cultura, democracia, opinião pública, preferência pública. 


\section{Introduction}

The entanglement of domestic politics with international affairs remains a fundamental and highly debated aspect of International Relations (I.R.) studies. Research on this intricate relationship between the domestic and the international has increased exponentially over the last two decades. Much of the existing literature acknowledges the multidimensionality of the domestic domain as with regards to its numerous actors, factions, private as well as governmental entities and their differing interests in policy outcomes ${ }^{1}$. While it is not within the scope of this paper to deliberate the intricacies of the international arena, its focus is on a vital yet highly debated and contentious component of the domestic domain - public opinion. The literature suggests that public opinion has the capacity to both constrain as well as influence preferred policies ${ }^{2}$. However, it may be argued that this public capacity is itself restrained by other societal peculiarities. The hypothesis being proposed in this paper therefore is that contextual nuances such as culture and democracy create regulatory boundaries that coerce public opinion, orient public preferences and regulate the participatory powers of the public.

As it relates to the empowerment of this public, recent appeals for increased civilian involvement in policymaking processes are poised to favor the resurgence of an actively participatory public in policy deliberations. One such petition for example, was witnessed on May 22, 2014 when a National Policy for Social Participation was tabled before the Brazilian Legislative Assembly via presidential decree $\left(\mathrm{N}^{0}\right.$ 8.243). The main purpose of this decree was to foresee the creation of mechanisms that would favor greater integration and participation of civil society in the "formulation, execution, monitoring and evaluation of public programmes and policies, towards an improvement in public administration".

This undoubtedly ambitious initiative has been greeted with mixed reactions with those in opposition pointing to civil society's unspecialized knowledge base and lack of the requisite training to adequately opine on issues of policy and public administration. The objective of this paper is not to make arguments for or against a kibitzer populace as with regards to policymaking. Notwithstanding, the public's apparent impasse is worth noting. In other words, the public is construed as being an element of the domestic arena with powers to influence policy, yet it (the public) is itself regulated by contextual forces. 
The matter at hand therefore is the identification and inspection of those factors that contribute to this characterization of the public, its opinions and its preferences. To this end, culture and democracy are examined on the basis of their influence over public preferences and opinion about policies, specifically trade related policies. This will be done with two objectives in mind; firstly to situate 'public' opinion in relation to the previously mentioned socio-political indicators, and secondly, to compliment the already vast body of literature on the public opinion - policy research agenda. In this way, culture's contribution and relevance to this research agenda will be substantiated. Based on the literature, both democratic rule and national culture have direct repercussions on the public's interests, opinions and policy preferences. In the causal dilemma that exists between these two 'regulators' however, culture is regarded as exercising the determining role.

The rest of the paper is divided into three sections. The first consists of a meticulous contextualization of 'public' opinion, with the aim of ascertaining a clear understanding of what / who are contemplated as the 'public'. This is especially important for two reasons: 1) because of the conflicting conceptual points of view among public opinion scholars in the literature, and 2) because providing this conceptual 'lay of the land' at the outset will ensure that the readers can easily accompany the rest of the paper. In the second section a historical and evolutionary review of democracy sets the tone for discussing the implications modern models of democracy have on public participation in policymaking and the 'democratizing' of policy deliberations.

A substantial part of this paper is dedicated to the establishment and discussion of culture as a determining factor in public preference and opinion about policies. To this end, the third section is dedicated to both situating culture within the public opinion - policy literature as well as recapitulating the evidence from theoretical, empirical and formal research models that demonstrate culture's relevance to trade policies, patterns and partnerships.

The paper ends with a brief assessment of the state of the art on the power of the public and the ability of its opinion to influence and inform issues of policy. While the advent of 'global politics' and innovations in technology have fostered a new era of democracy with a highly interconnected 'global civil society', culture persists as a compass that orients public preferences and opinions about trade policies. As far as affording greater public participation in 
policymaking therefore, the challenge to politicians is to develop a socio-politically dynamic framework that prioritizes the cultural peculiarities of their society.

\section{The Essence of a 'Public'}

Scholars of collective behavior have categorized forms of human conglomerations by their varied motivations, behaviors, level of interpersonal relationships and required organizational structure. Thus, a precise measure of what is 'public' opinion would necessarily require its preliminary characterization and distinction from the other utterances generated throughout society. In the second edition of their book Public Opinion, Glynn, C.J; et.al (2004) classify social formations into three major groupings: crowds, masses and publics. Referencing the work of Gustave Le Bon, Glynn, et.al describe crowds as social groupings that are motivated by common emotions, whose members possess minimal personal accountability and display a sense of 'invincibility' which results in a "contagion of ideas and feelings[...] that produce rapid shifts in behaviors" (p.17).

Mass formations on the other hand are motivated by a common interest, event or occurrence, and its actions lack intentionality due to the limited interpersonal relationship among its members. In what they describe as a 'positive contrast' to the aforementioned social groupings Glynn, et.al (2004) distinguish the 'public' by its rational, critical and organized grouping, which produces issue responses that are minimally controversial and essentially discourse based. Given its subtle differentiation from the others, the authors suggest that any loss of the reasoning or critiquing capabilities would resultantly transform a 'public' into a crowd.

Notwithstanding these broad classifications provided by Glynn, et.al (2004), there continues to be a lack of consensus in the literature about whose opinions in fact, represent those of the 'public'. To this end, scholars have concentrated their debates around three classes of society: individuals, interest groups and the elites. Among the proponents who prioritize individual opinions two distinct yet overlapping perspectives were identified in the literature. On the one hand, there are those who defend the use of aggregated individual opinions, via surveys and polls, while on the other hand are those who suggest taking a majoritarian approach in determining public opinion. Supporters of the latter make the argument that "we need to think of 
public opinion as the equivalent of social norms - that the values and beliefs of the majority of citizens are the true basis of public opinion" (Glynn, et.al; 2004, p.20). Noting the wide acceptance of surveys and polls however, Glynn, et.al (2004) also highlight the benefits of the aggregated individual opinions which is thought to provide a direct quantitative means of capturing public mood, and imitates the 'one man, one vote' principle of democratic societies.

Interest groups are seen as powerful representatives of community concerns and are thought to promote discussions in defense of issues relevant to the society. Ideally, these groups evolve from the conglomeration of individuals' concerns on issues and are deemed the voice of the 'public' since "policymakers and journalists are more likely to be interested in group opinion than in single opinions" (Glynn, et.al; 2004, p.22).

The third social class in contention is society's elites, which often contemplates the role of the media. Regarded as the reservoir from which the previously discussed societal classes receive their information, these 'social leaders' are thought to embody the voice of the 'public' because of their key role in the dissemination of information and the consequential capability of contributing to the formation and possible manipulation of the beliefs, attitudes and opinions of the populace. Those who ascribe to this 'specialist public' point of view seek to contradict the logic of an 'omnicompetent citizen', 3 and defend their perspective by making insinuations similar to that of Walter Lippmann who adamantly argued that "the common citizen could not possibly stay informed on all affairs of state and, given this impossibility, could hardly be relied upon to produce intelligent opinions on all public affairs" (Walter Lippmann apud Glynn, et.al; 2004, p.24).

All three of these ideals of the 'public' have encountered opposition and skepticism as it relates to these publics' ability to adequately and efficiently opine on policy issues. In assuming a contradictory perspective Van Ginneken $(2003)^{4}$ is emphatic in his view that 'public' opinion is "not a static sum of individual opinions but a dynamic process which continually evolves new and shifting patterns". For Van Ginneken, the 'public' is an "ensemble of publics" and a configuration which facilitates the interweaving of protagonistic, neutral as well as antagonistic discourses on issues. While his view of the 'public' clearly contradicts the credibility of 
individual opinions (aggregated or majoritarian), Van Ginneken calls attention to the essential and core attributes of a 'public'- that of its rational and discourse oriented organization.

\section{The Boundaries of Democracy}

Liberalism, conservatism, capitalism, socialism, Marxism, corporatism, anarchism, even democratic ideas, all face a world that in its form and thrust confounds the crucial assumptions, requirements, descriptions, predictions, hopes, or prescriptions they express.

Robert A. Dahl

Dilemmas of Pluralist Democracy - Autonomy vs. Control

In the $9^{\text {th }}$ chapter of their 2004 publication entitled Public Opinion, Glynn et al. present the argument that the power of 'public' opinion resides in its ability to not only constrain policies but to also act as a "force" that stimulates the continuity of favored policies. The effectiveness of these abilities is however highly dependent on the political as well as social circumstances surrounding the particular policy. Scholars of this opinion-policy nexus have identified several aspects of the political process that may exert regulative capabilities over public opinion. Named among such factors are: issue saliency, policy type, mode of representation, and the arm of government responsible for policy action (i.e. the president, congress or Supreme Court) ${ }^{5}$. Notwithstanding, constitutionally mandated periodic elections are the utmost of these political mediating factors given that they provide the citizenry with the power to reward (via election or reelection) or punish (via non-election) those officials they deem most and/or least coherent with their opinions and preferences.

On the premise that "elected leaders in a democratic nation will not deviate far from voters' opinions [...] by the time of the next election" [Robert] Shapiro suggests that "electoral accountability' is the most persuasive driving force in public opinion's causal impact on policy ${ }^{6}$. Glynn et al. (2004) concur with this point and affirm that "at election time leaders ignore public opinion at their own peril [since] they know that they or their party may have to answer for their past acts at the next election". For Jacobs and Shapiro (2002) however "the skilled politician prefers to take actions that advance both electoral goals and policy goals" and one way of accomplishing this is by employing a strategy of 'crafted talk' in which their rhetoric is tailored in such a way as to "lower the potential electoral costs to themselves and their supporters of not 
following the preferences of average voters while increasing the electoral costs to rival politicians". 7 Thus, Jacobs and Shapiro (2002) make the claim that,

As a general rule, politicians who enjoy long careers in elected office are skilled at weighing the political costs and benefits of their statements and actions. Their perceptions of the costs and benefits of their behavior affect their motivation and willingness to pursue two distinct goals. The first goal is electoral and suggests pleasing as many voters within their constituencies as possible. The second goal is to enact the policies they and their supporters most desire

It is therefore possible to infer that the actions and motivations of elected officials are oriented towards an optimization of both their pursuit of (re)election as well as the promotion of their preferred policies. For Jacobs and Shapiro (2002) these interests reflect a classic case of elected officials "want $[$ ing $]$ to have the best of both worlds".

The platforms of public office, whether local or executive, transnational or multilateral, are however inundated with discourses, manifestos and declarations that incite an adherence to 'democracy'. This fervent propagandizing has resulted in a muddling of the 'democratic' waters, evidenced by the challenge in distinguishing between democracy - the often idealized system of governance - and democratic praxis. According to Dahl (1982) these 'porous boundaries' between democratic theory and practice are primarily due to the fact that,

The most powerful ideologies of our age all suffer from having acquired their shape and substance in the eighteenth and nineteenth centuries, or very much earlier, before the world in which we now live had come fully into view.

The word democracy is derived from the Greek "demos", meaning 'the body of people', 'the populace', and refers to a political system in which all eligible citizens have equal rights, responsibilities and authority over their government. Implemented in ancient Greece, democracy was founded on the principle of 'majority rule' and in its truest form sought to arm the citizenry with direct and complete power over all aspects of public office. A divergence from this type of "mass democracy" 8 was brought on by the feverish worldwide multiplication of these democratic ideals. This however lead to what some scholars have coined 'modern democracy' (Dahl, R.A; 2006), or the 'third wave of democracy' (Huntington, S.P; 2003), which is characterized by the

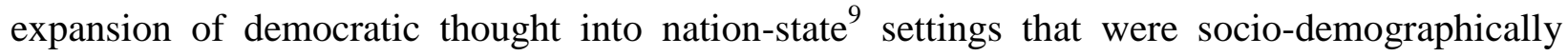


more complex than the initial Greek context, resulting in the generation of numerous derived models of democracy. In a vividly concise description of this transfiguration of democracy [Robert] Dahl, in his 1982 publication, expressed that:

The increasing application of democratic ideas to nation-states from the seventeenth century onward required new political institutions radically different from those appropriate to city-states. The new institutions both reflected and fostered changes in ways of thinking about democracy itself. As new forms came to be justified by older ideas, changes in political consciousness occurred that were often subtle, elusive, and confusing. Today the term democracy is like an ancient kitchen midden packed with assorted leftovers from twenty-five hundred years of nearly continuous usage. (emphasis added)

Two noteworthy occurrences accompanied this 'exportation' of democratic ideals. The first is the relatively steady increase observed in the number of countries under democratic governance substantiated by the leap from 30 countries between 1974 and 1990 (Huntington (2003) to 90 countries in $2012^{10}$. The second set of repercussions was an emergence of several contemporary theories of democracy, some of which (namely: the Polyarchal, Madisonian, Pluralist and Populistic theories) receive prestige in the political science literature due to their contribution to the conceptualization of modern democratic thought which formed the basis for several constitutional reforms. [Carole] Pateman speaks to this "rejection of earlier democratic theories" in his 1970 publication Participation and Democratic Theory, in which he makes the claim that,

There was a further factor that helped along the process of the rejection of earlier democratic theories, and that was the now familiar argument that those theories were normative and "value-laden," whereas modern political theory should be scientific and empirical, grounded firmly in the facts of political life.

As it relates to the adherence / transition to democratic governance several modifications to democratic praxis are mentioned in the literature. An example of change that is relevant to the discussion about democracy's orientation of public opinion is the deviation from a direct participation of the populace in matters of government to a model of elected representation, referred to in the literature as 'representative democracies' (Dahl; 2006). The principal repercussion of this model however being the role and power attributed to the political representatives. 
While under this model the populace continues to have a voice, or more appropriately a vote and/or opinion about salient issues, the agenda setting decisions pertinent to the determination of policy priorities, configuration, execution and timelines, etc. rest solely with the body of elected representatives. As a result, the literature affirms there has been an exponential increase in the number and frequency of public opinion polls and surveys since the mid to late $20^{\text {th }}$ century, this because they are being frequently relied upon to provide a measure of 'public' mood and preference. In light of this increase in opinion polling initiatives analysts have presented mixed views about public opinion's continued ability to inform and/or influence policy.

Manza, et.al. (2002) groups these differing views into three categories: (1) those who regard public opinion's influence favorably and allude to the existence of a "strong, persisting impact of public opinion on public policy"; (2) those who consider the opinion surveys to be merely the politicians' means of indulging the 'public'; and (3) those who see increased polling as synonymous with a "growing reliance on public relations" and the establishment of a state of “permanent campaigning”. In spite of these differing points of view, Manza, et.al; (2002) do not disregard public opinion's ability to influence policy.

On the contrary, the authors call attention to the contribution of technological and methodological innovations in refining the opinion survey and polling processes in order to "improve $[$ our $]$ understanding of public opinion". In a similar fashion, Shapiro (2011) asserts that the data generated from polling initiatives serve both to orient political leaders about the opinions of the public as well as to facilitate political science research. To this end, [Robert] Shapiro (2011) considers the increased polling and opinion surveys to be,

[...] a way of regularly measuring people's privately held opinions that leaders might act on, not just the opinions of those who choose to influence leaders through political activity [...] and political scientists and others could use these data to examine more analytically than before the impact of the mass public on government policies

The operationalization of public opinion within a republic is often confounded with a similar undertaking in a representative democracy, possibly because of the array of civil liberties afforded to the citizenry of the former, which could arguably be described as the appropriation of democratic values and principles by a nondemocratic regime. In the Federalist papers, [James] 
Madison attributes this error to "the artifice of some celebrated authors, whose writings have had a great share in forming the modern standard of political opinions" ${ }^{11}$. Madison (1787, p. 69) proposes a clear distinction between the criteria and social prerequisites of a democracy and those of a republic by affirming that,

[...] in a democracy, the people meet and exercise the government in person; in a republic they assemble and administer it by their representatives and agents. A democracy consequently must be confined to a small spot. A republic may be extended over a large region.

While Madison's distinction presumably focuses on the characteristics of the 'turbulent democracies of ancient Greece' his blatant disregard for what he referred to as 'fallacious theories' - that convey to a republic observations that are applicable to a democracy - was evident in his subsequent delineation of what he referred to as the 'natural limit' of a democracy and the 'natural limit' of a republic ${ }^{12}$. Thus, Madison $(1787$, p. 70$)$ proposes that:

The natural limit of a democracy is that distance from the central point, which will just permit the most remote citizens to assemble as often as their public functions demand; and will include no greater number than can join in those functions; so the natural limit of a republic is that distance from the center, which will barely allow the representatives of the people to meet as often as may be necessary for the administration of public affairs.

Notwithstanding these painstaking descriptions and clear differentiation between a republic and a democracy (albeit representative), the advent of what are referred to in the literature as 'cosmopolitan democracies' (Archibugi; 2004) and 'cosmopolitan polity' (Held; 2004) have further blurred the demarcation of public articulation, participation and influence over policy. Archibugi (2004) explains that the concept of cosmopolitan democracies was borne from an intent to "globalize democracy while, at the same time, democratizing globalization" and by so doing offset the "implementation of a democratic society within, among and beyond states" 13 . Though it is well beyond the scope of this paper to explore 'global democracy' at the level of interstate, multilateral and/or transnational relations (i.e. relations on the international sphere), it's repercussions in the domestic domain, as with regards to the power attributed to public opinion on issues of policy, are of particular interest and will be briefly examined. 
Held (2004) alludes to a 'framework of cosmopolitanism polity' which is comprised of a set of principles that "can be universally shared, and can form the basis for the protection and nurturing of each person's equal interest in the determination of the institutions which govern their lives" In this regard, [David] Held suggests that such 'cosmopolitan values' are not made up of political ideals but rather consist of a "collectively sanctioned framework of actions [...in which] public power can be conceived as legitimate". The 'public' in this framework would therefore take on new configurational and functional dimensions described by (Held; 2004) as a 'multilevel citizenship' in which,

The meaning of citizenship shifts from membership in a community which bestows, for those who qualify, particular rights and duties to an alternative principle of world order in which all persons have equivalent rights and duties in the crosscutting spheres of decision-making which affect their vital needs and interests.

Facilitated by the innovations in technology and telecommunications, this 'multilevel' and 'multidimensional' citizenship is further characterized by its capacity to surpass national as well as regional boundaries. This is because its membership is not determined by the exclusivity of a territorial community, but by "general rules and principles which can be entrenched and drawn upon in diverse settings [resulting in] a world increasingly defined by multiple forms of citizenship" (HELD, 2004).

Resulting from this interconnected 'public' would therefore be the establishment of a network of 'global civil societies' ${ }^{14}$ which would have greater impact and more far reaching influence on policy issues. [John] Ruggie's proposal of a 'global public domain' bears significant semblance to that of Held's 'global civil society' specifically as it relates to having no centralized coordinating mechanism and "plays out in an interconnected manner within and across different social sectors and in domestic as well as transnational arenas” (RUGGIE, J; 2004).

While the concept of a 'global civil society' is sustained by the notion of a web of global 'publics' however, the 'global public domain' is suggestive of an ample global framework in which systems of national and transnational governance may be entrenched. In other words, a global public domain may be described as: 
$[\ldots]$ an institutionalized arena of discourse, contestation, and action [...] It is constituted by interactions among non-state actors as well as states. It permits the direct expression and pursuit of a variety of human interests, not merely those mediated (filtered, interpreted, promoted) by states. It 'exists' in transnational non-territorial spatial formations, and is anchored in norms and expectations as well as institutional networks and circuits within, across and beyond states. (RUGGIE, J; 2004)

Irrespective of their subtle differences, the models of public participation implied by both the 'global civil society' and the 'global public domain' make important contributions to discussions about the democratization of policy deliberations by attributing transnational and globally impacting powers to public opinion. The allegiance of the citizenry to national as well as regional cultural norms and traditions however raises the question of culture's correlation with democracy and democratic institutions in the determination of public opinions, interests and preferences. In other words, does the public make rational choices or are public opinions and preferences hinged on cultural orientations?

While a more meticulous explanation of this relationship follows in the ensuing section, the thesis herein proposed is that though cultural traditions as well as democratic principles and institutions influence political and economic behaviour, causality between these two variables is not easily determined and it is more likely a situation where culture contours democracy than the other way around ${ }^{15}$.

\section{The Boundaries of Culture}

Culture may be presumed an ambiguous concept due to the varied interpretations and significance that fall under its purview. Regardless of the differing viewpoints however, social scientists and scholars of comparative culture have configured an ample definition in which they regard culture as,

[...] a catchword for all those patterns of thinking, feeling, and acting [...] Not only activities supposed to refine the mind are included, but also the ordinary and menial things in life: greeting, eating, showing or not showing feelings, keeping a certain physical distance from others, making love, and maintaining body hygiene. (HOFSTEDE; G. 2010, p.5)

While this broad classification can serve as the backdrop for culture research in all areas of academia, Hofstede (2010) recommends a more succinct definition by proposing culture to be 
"the unwritten rules of the social game [...] the collective programming of the mind that distinguishes the members of one group or category of people from another" (emphasis added). It is worth noting that this group distinction that culture provokes is not restricted to territorial or geo-linguistic borders as is evidenced by the frequent formation of culturally oriented subgroups within any given society.

Hofstede (2010) addresses this issue in two ways. Firstly, in his further delineation of culture he attributes prominence to societal values rather than practices, and asserts that the former are "the stable elements in culture". Secondly, he identifies the repercussions of cultural 'rivalry' within territorial borders and asserts that,

Regional, ethnic, and religious cultures account for differences within countries; ethnic and religious groups often transcend political country borders. Such groups form minorities at the crossroads between the dominant culture of the nation and their own traditional group culture (HOFSTEDE, G et.al; 2010, p.45, emphasis added by author)

Regarding a nation-states' system of governance, proponents of culture as a determining variable for democracy posit that a country's predominant cultural norms and values are instrumental in orientating political processes and priorities. Huntington (2003) argues this point in his paper entitled "Democracy's Third Wave", in which he presents the argument that the so called "stable elements of culture" can in fact obstruct and even deter a transition and / or adherence to democracy. It is on the basis of these cultural differences therefore, that Huntington justifies the assumption that Western cultures are more pro-democracy than their counterparts.

For Huntington (2003), "the world's great historic cultural traditions vary significantly in the extent to which their attitudes, values, beliefs, and related behavior patterns are conducive to the development of democracy". Arguably, Huntington's thesis bears some similarity to that presented by Hofstede (2010), who contends that "a country's values are strongly related to the structure and functioning of its institutions" (p.24).

Modernization theorists such as Ronald Inglehart however oppose this point of view and ascribe to the thought that it is the increased industrialization and economic development in a society that causes "cultural shifts away from traditional value systems" and towards postmodern values 
that are conducive to democracy (Inglehart, 2000). Hence for Inglehart, what differentiates one society from the next aren't their traditional norms and values per se but rather their degree of "survival" versus "self expression" values. It is on this premise that the World Values Survey (WVS) projects the existence of 'distinctive cultural zones' that are determined by county's traditional versus secular and survival versus self expression values, and which resultantly establishes a measure of cultural propinquity among countries. To this end, Inglehart (2000) affirms that,

Distinctive cultural zones exist and they have major social and political consequences, helping shape important phenomena from fertility rates to economic behavior and democratic institutions [...] Societies vary tremendously in the extent to which they emphasize "survival values" or "self-expression values." Societies that emphasize the latter are far likelier to be democracies than societies that emphasize survival values.

The WVS map (shown below) therefore graphically displays these cultural zones and facilitates the visualization of country locations based on their cultural similarities. The results from the 2005 - 2008 world values survey proposed a total of nine (9) cultural zones (see WVS map below). Though on its own this classification may appear to not have direct implications for the discussions contained within the scope of this paper, it is introduced here because of its potential as a valuable tool for future empirical research into the culture-opinion-policy connection.

Figure 1 The World Values Survey (WVS) Cultural Map (2005-2008)

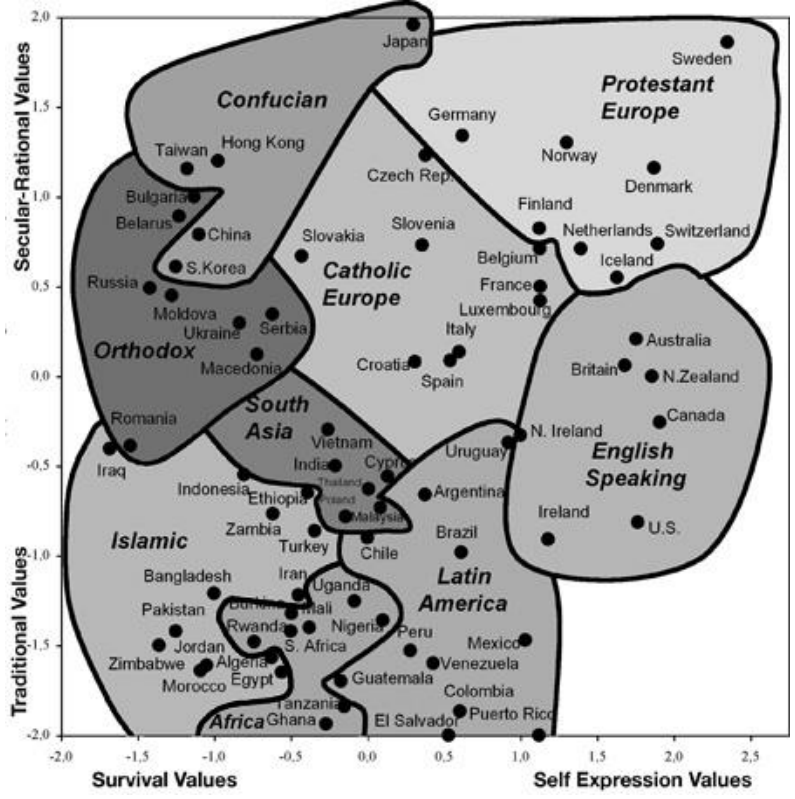

Source: World Value Survey Map accessed via www.worldvaluessurvey.org 
Constructivist theorists have long grappled with defining culture's role and application to the context of International Relations studies. One such theorist is Alexander Wendt who in his 1999 publication Social Theory of International Politics ${ }^{16}$ surmised that, "culture is not a sector or sphere of society distinct from the economy or polity, but present wherever shared knowledge is found [...] that is both common and connected between individuals" (p.141). For Wendt, this 'shared knowledge' to which he refers would often "stem from domestic or ideological considerations".

This thesis of culture as a segment of an ideational social structure was subsequently countered by scholars of The English School who proposed the concept of culture within the framework of a 'world society'. Buzan (2004) cites Bull's (1997) definition of a world society and highlights that it refers to:

[...] not merely a degree of interaction linking all parts of the human community to one another, but a sense of common interest and common values on the basis of which common rules and institutions may be built. The concept of world society in this sense stands to the totality of global social interactions.

There are noteworthy similarities between Bull and Wendt's conceptualization of culture especially as it relates to the element of common knowledge and socialized values they both address. Speaking specifically to the discussion of cultures' role in the orientation of state behavior however [John W.] Burton defends the position that "state behavior cannot be understood without taking into account the wider context of human interactions" which are delineated and grounded by the predominant norms and values of their society. (Burton (1972) cited by Buzan, B; 2004)

Regarding culture's direct relation to public opinion, Glynn, C.J; et.al (2004) allude to the existence of an 'intertwined' and 'inseparable' public opinion - culture nexus, which is best reflected in opinion survey data. For these scholars, public opinion research has the ability to capture the norms, values and sentiments of the survey respondents, and in doing so also reveals culture's deep connectedness with public opinion. 
Evidence from empirical research has also substantiated culture's relation to public preference and opinion about policies. A fitting example is O'Rourke \& Sinnott's (2001) work on the determinants of trade policy preferences, the results of which suggested that nationalist attitudes do influence individual's trade policy preferences. In their survey based research, the authors present evidence of relations between patriotism, chauvinism and protectionist attitudes, and conclude that individual policy preferences were "heavily influenced by non-economic [...] cultural or ideological factors".

Similarly, Shen \& Edwards' (2005) survey experiment investigated the degree to which individuals' cognitions and opinions on policy issues were affected by the interaction of their core values with value based media frames. Utilizing a quasi-experiment design, the authors concluded that "individuals' preexisting values had important implications on audience issue thoughts and opinions". These findings were attributed to the social cognitive theory of accessibility, in which "chronically accessible constructs such as values can [...] lead to automatic information processing, allowing people to detect and process relevant information even when attentional resources are diverted elsewhere"

As it relates to culture possibly having a direct and influential role on policy outcomes, empirical research has shown a noteworthy correlation between facets of foreign policy (specifically trade related policies) and cultural proximity. Such evidence is provided by Guo (2004) for example, whose work demonstrates that linguistic as well as religious affinity have a direct relation to the retardation and/or encouragement of foreign trade. In his investigation [Rongxing] Guo examines the cross national panel data for the U.S and China over the period 1987 - 1997 and came to the conclusion that "linguistic links have become more important in foreign trade than geographical proximity [and its] influence on trade is more significant in China than in the U.S.". Regarding religion, Guo (2004) concludes that "China's foreign trade is more sensitive to the religious links with its trade partners than the U.S.”.

Additional data in support of this relation between cultural proximity and public opinion was provided by Linders (2006) who examined the impact of culture on trade patterns. Based on the assumption that cultural differences present intangible barriers to trade, [Gert-Jan] Linders suggests that "lack of information and knowledge on foreign cultures, and distance in terms of 
cultural values and norms raise economic distance, and affect transaction costs of trade". The results obtained therefore indicate that "familiarity matters for trade", and "country pairs with a similar official language, religion and colonial past, trade more because these cultural and historical links increase the extent to which countries are familiar with each other" ${ }^{\prime 1}$.

Though costs associated with geographic distance present the most obvious obstacles to trade ${ }^{18}$ tariff barriers, incompleteness of information on foreign markets, differences in the institutional environment and cultural differences between countries are identified by Linders as equally influential promoters of 'economic distance" ${ }^{19}$. Thus, it may be inferred that countries with similar cultural orientations, classified by Inglehart \& Welzel (2010) as countries which demonstrate minimal "cross national differences", would tend to have reduced economic distance resulting in increased trade flows, and favorable public opinion about these trade partnerships.

The application of formal methods to aspects of the culture-opinion-trade research agenda has also contributed to the consolidation of culture as a relevant and indispensible 'non-tariff barrier to trade', having demonstrated culture's role in the prediction of trade patterns and preferences. One such approach has been the adaptation of a gravity model to include elements of culture in order to estimate culture's impact on bilateral trade patterns. For Ku \& Zussman's (2010) a gravity model of trade is the approach most often used to estimate the effect of intangible barriers (especially language) on international trade. Van Bergeijk \& Brakman (2010) likewise value the use of gravity models as an "empirical tool" for estimating the effects of non-tariff barriers to trade, and affirm that,

Economic factors such as tariffs and non-tariff barriers have been included in applications of the gravity model, but also "non-economic" factors have been included, such as cultural differences, differences in religion, language (dis)similarities, the presence or absence of former colonial ties, institutional differences, differences in technological development, and so on. The list of applications is long and, most remarkably, empirical tests show that this simple idea is very successful from an empirical point of view and is able to show that many economic phenomena between different locations can empirically be described by a gravity equation. 
Modeled after Newton's theory of gravitational attraction, the basis of the gravity model of international trade (see eq. 1 below) proposes that trade propensity between two countries is dependent on the economic mass of either country $(\mathrm{Y})$, proportional to the distance between their centres of gravity (D) squared. Thus the shorter the geographical distance and the higher the economic mass, the more likely there is to be increased trade flows.

Eq. 1

$$
\operatorname{Trade}_{a b}=G \cdot \frac{Y_{a} Y_{b}}{D_{a b^{2}}}
$$

In her work on "The Impact of Institutions, Culture and Distance on Patterns of Trade" Linders (2006) performed an adaptation of the traditional gravity model so that the estimation of economic mass was represented by GDP because it is representative of the market size for both the importing as well as the exporting country. According to Linders (2006) this adaptation was justified given the fact that "the market size of the importing country reflects the potential demand for bilateral imports, while GDP in the exporting country represents the potential supply of goods from that country". In addition, other measures of economic mass and/ or economic distance, such as income per capita, price levels, product variety, etc. were excluded such that only estimates for cultural (dis)similarity, specifically language and religion were contemplated, in order to accurately estimate the influence of these cultural variables on the restriction or enhancement of trade intensity. Since the empirical estimation the gravity equation is usually expressed in logarithmic form, Linders' modified gravity equation was therefore as follows ${ }^{20}$ :

$$
\ln \text { TRADE } a b=\ln G+\beta 1 \ln (\operatorname{GDP} a \mathrm{GDP} b)+\beta 2 \operatorname{lnDISTANCE} a b+\beta 3 \text { LANGUAGE } a b+\beta 4 \text { RELIGION } a b
$$

A critique of Linders' approach that is worth noting however has to do with the fact in order to obtain a more precise measure of cultural similarity the cultural diversity of country pairings ought to be taken into accounted. In this way, the model should look beyond the predominant cultural expressions of the countries and incorporate the peripheral languages and religions as well.

Other studies have taken different approaches to the measure of cultural similarity within gravity equations. The model used by [Jeffrey A.] Frankel in his 1997 publication was referred to by Guo (2004) who explained that the model employed a $0-1$ dummy variable in which 1 represent 
having cultural similarity, while 0 stood for not having cultural similarity ${ }^{21}$. In his own research however Guo (2004) recommends the use of a "comprehensive measure of cultural links between [..] pairs of economies" based on the population ratios of the different cultural groups in each country pair and taking into account the sharing of land borders given its influence on trade.

To account for the matter of sharing land borders Guo's (2004) approach utilizes a dummy variable for adjacency where, $1=$ sharing land borders and $0=$ not sharing land border. Another interesting element of Guo's research was the attribution of +1 to trade between all country pairs in order to make the natural logarithm of trade mathematically meaningful when there is no trade between country pairs (i.e. trade $=0$ ). Guo (2004) therefore proposes the following modified gravity equation of international trade:

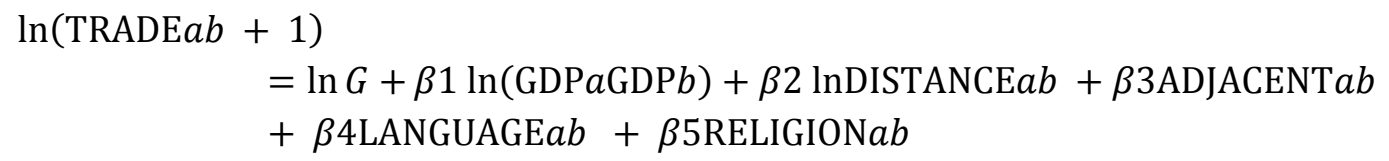

The adaptation of Newton's gravity equation into a model for estimating culture's impact on international trade patterns, intensity and preferences is yet another tool available to researchers of the culture-opinion-policy agenda. Overall, the evidence provided by the theoretical, empirical and formal approaches highlighted in this section of the paper substantiates the hypothesis that not only does culture matter to discussions of a public opinion-policy connection but it is also an indispensible mediating and determining variable for trade related policies.

\section{A Brief Discussion of the Findings}

It follows from what I have argued that the general will is always rightful and always tends to the public good; it does not follow that the deliberations of the people are always equally right. We always want what is advantageous to us but we do not always discern it. The 'people' is never corrupted, but it is often misled; and only then does it seem to will what is bad.

(Jean-Jacques Rousseau - The Social Contract)

The National Policy for Social Participation (Presidential decree $\mathrm{N}^{0}$ 8.243) tabled before the Brazilian Legislative Assembly on May 22, 2014 recommend the fostering of greater integration and participation of the civil society in the "formulation, execution, monitoring and evaluation of public programmes and policies, for the improvement of public administration". While this 
initiative may receive favorable reactions from civil society groups it has been met with substantial opposition and skepticism from some government representatives.

A possible source of this disagreement between the civil society and the government representatives may be doubts on the side of the latter about how such a system of 'public participation' in policymaking could be effectively executed while yet maintaining the integrity of the political process as stipulated by the appropriated model of democratic representation. While some scholars such as V. O. Key Jr. defend the view that "unless mass views have some place in the shaping of policy all the talk about democracy is nonsense" (V. O. Key Jr. apud Glynn. et.al, 2004), the public's ability to inform and effectively influence policy remains a point of discord in the literature and among the public opinion - policymaking fraternity.

In light of the ample and all encompassing views of what constitutes the 'public' it is pertinent to question whether the opinion of this / these 'publics' can in fact provoke favorable policy responsiveness. The exponential increase in opinion polling initiatives witnessed in the mid to late $20^{\text {th }}$ century is suggestive of the value policymakers have attributed to poll and survey data, thought to indicate 'public' mood and preference, however Shapiro (2011) cautions against the possible misrepresentation of this polling and survey frequency on the basis that same may be less representative of democracy in action and more a matter of "cover[ing] topics and issues that are salient and important to pollsters". Glynn, et,al; (2004) also address the topic of issue saliency and posits that policies tended to be more responsive to salient issues and "especially those that clearly had potential electoral consequences"(p.390).

Policy responsiveness as a measure of the public's ability to effect change has however displayed contradictory results, some scholars showcasing policy changes congruent with public preferences, with others suggesting just the opposite. In an attempt to present a more neutral perspective of the state of the art $[\mathrm{Paul}]$ Burstein makes the claim that,

Overall the finding that opinion influences policy is amazingly robust - most studies show opinion affecting policy regardless of how opinion, policy, and the relationship between them is measured. It's not possible to say how strong the relationship is, or how the strength depends on circumstances ${ }^{22}$. 
New technological innovations have given a global configuration to our modern world which "calls into question the traditional demarcations between the domestic and the foreign and between the territorial and the non-territorial" ${ }^{, 23}$. Notwithstanding the constraining capabilities of culture and democracy over public opinion has been firmly established as with regards to their regulatory roles over the modus operandi of societies and the consequent implications on the public's interests, opinions and policy preferences.

Modernization theorists like [Ronald] Inglehart suggest that economic developments are responsible for the occurrence of gradual culture shifts away from traditional ideals to values such as interpersonal trust, tolerance and participation in decision making that are more conducive to democracy ${ }^{24}$. This rationale leads to a causality dilemma between democracy and culture, such that on the one hand it may be presumed that richer countries having appropriated certain values are more democratic, while on the other, the transition to democratic governance is responsible for causing changes in value orientations. While the examination of this causality dilemma exceeds the scope of this paper, Inglehart's determination of culture as the more likely protagonist is accepted. Specific to culture's coercing capabilities over public opinion, and its relevance to discussions about the democratization of policy deliberations therefore, Inglehart aptly recommends that:

By the 1990s, observers from Latin America to Eastern Europe to East Asia were concluding that cultural factors played an important role in the problems they were encountering with democratization. Simply adopting a democratic constitution was not enough. Cultural factors have been omitted from most empirical analyses of democracy partly because, until now, we have not had reliable measures of them from more than a handful of countries. When cultural factors are taken into account [...] they seem to play an important role.

(INGLEHART, R; 2000)

In the quest for greater public participation in policy deliberations therefore, it is not enough to stipulate the increased presence of civil society's representatives at policymaking forums. Policymakers must consider their public / publics and develop a socio-politically complex and dynamic framework that is oriented by the cultural values of their society. 


\section{NOTES}

${ }^{1}$ See Robert D. Putnam, Diplomacy and Domestic politics: the logic of two level games. International Organization, Vol. 42, No. 3. 1988, pp. 427-460; Daniel W. Drezner, Locating the Proper Authorities: The Interaction of International and Domestic Institutions. University of Michigan Press, 2003.

${ }^{2}$ Carroll J. Glynn, Susan Herbst, Garrett J. O’Keefe, Robert Y. Shapiro, Mark Lindemann; Public Opinion. Second edition. Westview Press,2004, p. 358.

${ }^{3}$ See reference to Walter Lippmann (1925), The Phantom Public. In Carroll J. Glynn, Susan Herbst, Garrett J. O’Keefe, Robert Y. Shapiro, Mark Lindemann; Public Opinion. Second edition. Westview Press, p. 358.

${ }^{4}$ Jaap Van Ginneken. Collective Behavior and Public Opinion: rapid shifts in opinion and communication. Lawrence Earlbaum Associates Publishers, New Jersey, 2003

5 See, Robert Y. Shapiro. Public Opinion and American Democracy Public Opinion Quarterly, Vol. 75, No. 5, 2011, pp. 982-1017; Carroll J. Glynn, Susan Herbst, Garrett J. O’Keefe, Robert Y. Shapiro, Mark Lindemann; Public Opinion. Second edition. Westview Press, chapter 9.

${ }^{6}$ See, Robert Y. Shapiro. Public Opinion and American Democracy Public Opinion Quarterly, Vol. 75, No. 5, 2011, pp. 982-1017

${ }^{7}$ See, Lawrence R. Jacobs and Robert Y. Shapiro. 'Politics and Policymaking in the Real World - crafted talk and the loss of democratic responsiveness' in Jef Manza; Fay L. Cook and Benjamin I. Page, eds., Navigating Public Opinion: polls, policy and the future of American democracy. Oxford University Press, 2002.

${ }^{8}$ Ronald Steele cited by Carroll J. Glynn, Susan Herbst, Garrett J. O'Keefe, Robert Y. Shapiro, Mark Lindemann; Public Opinion. Second edition, Westview Press , 2004.

${ }^{9}$ Used as a synonymous term for the word country. Both expressions are used interchangeably throughout the text

10 Taken from: Freedom in the World - Democratic Breakthroughs in the Balance (2013), accessible via: http://www.freedomhouse.org/

${ }^{11}$ See, James Madison (1787) 'Federalist Fourteen' in Alexander Hamilton; James Madison and John Jay. The Federalist. J.R.Pole, eds; Hackett Publishing Company, Inc. Indianapolis/Cambridge, 2005.

12 See, James Madison (1787) 'Federalist Fourteen' in Alexander Hamilton; James Madison and John Jay. The Federalist. J.R.Pole, eds; Hackett Publishing Company, Inc. Indianapolis/Cambridge, 2005.

${ }^{13}$ Emphasis added by author

14 See, David Held Democratic Accountability and Political Effectiveness from a Cosmopolitan Perspective. Government and Opposition, volume 39, issue 2, January 2004, pp. 364-391

15 See, Ronald Inglehart. 'Culture and Democracy' in Culture Matters: How Values Shape Human Progress, Lawrence E. Harrison, Samuel P.Huntington - editors, Basic Books, New York, 2000

${ }^{16}$ Alexander Wendt. Social Theory of International Politics; Cambridge University Press, 1999. 
17 See, Gert-Jan Linders. (2006) Intangible Barriers to Trade: the impact of institutions, culture and distance on patterns of trade. Doctoral Thesis, VU University, Amsterdam

${ }^{18}$ See, Paul Wonnacott and Mark Lutz. 1989. "Is There a Case for Free Trade Areas?” In Schott, J.J.(ed.) Free Trade Areas and U.S. Trade Policy, pp. 59-84. Washington, D.C.: Inst. Int. Econ

${ }^{19}$ Concept introduced by Linders (2006) and defined as defined as a "multidimensional concept that incorporates all barriers to trade that raise the effective distance between countries"

${ }^{20}$ See, Gert-Jan Marie Linders. (2006) Intangible Barriers to Trade: the impact of institutions, culture and distance on patterns of trade. Doctoral Thesis, VU University, Amsterdam

${ }^{21}$ Reference to Jeffrey A. Frankel (1997) Regional Trading Blocs in the World Economic System. In GUO, R. (2004) How Culture Influences Foreign Trade: evidence from U.S and China. The Journal of Socio-Economics; vol 33

${ }^{22}$ Paul Burstein cited by Shapiro, R Y. (2011) Public Opinion and American Democracy. Public Opinion Quarterly, Vol. 75 , No. 5

23 See, David Held Democratic Accountability and Political Effectiveness from a Cosmopolitan Perspective. Government and Opposition, volume 39, issue 2, January 2004

${ }^{24}$ See Ronald Inglehart. 'Culture and Democracy' in Culture Matters: How Values Shape Human Progress, Lawrence E. Harrison, Samuel P.Huntington - editors, Basic Books, New York, 2000 


\section{REFERENCES}

Archibugi, D. (2004) Cosmopolitan Democracy and its Critics: a review. European Journal of International Relations. SAGE Publications and ECPR-European Consortium for Political Research, Vol. 10(3): 437-473

Buzan, B. (2004) From International to World Society? English school theory and the social structure of globalization. Cambridge University Press.

Dahl, R. A. (1982) Dilemmas of Pluralist Democracy: autonomy vs. control, Yale University Press.

Dahl, R. A. (2006) A Preface to Democratic Theory (expanded edition), The University of Chicago Press.

Glynn, C. J; Herbst, S; O’Keefe, G. J; Shapiro, R. Y; Lindemann, M. (2004) Public Opinion Second edition, Westview Press

Guo, R. (2004) How Culture Influences Foreign Trade: evidence from U.S and China. The Journal of Socio-Economics; vol 33.

Held, D. (2004) Democratic Accountability and Political Effectiveness from a Cosmopolitan Perspective. Government and Opposition, volume 39, issue 2.

Hofstede, G; Hofstede, G. J; Minkov, M (2010) Cultures and Organizations Software of the Mind: intercultural cooperation and its importance for survival. The McGraw Hill Companies.

Huntington, S. P (2003) Democracy's Third Wave in: Robert A. Dahl; Ian Shapiro; Jose Antonio Cheibub, (eds.), The Democracy Sourcebook. Massachusetts Institute of Technology, 2003

Inglehart, R. (2000) Culture and Democracy in: Harrison, Lawrence E; Huntington, Samuel P. (eds.), Culture Matters: How Values Shape Human Progress, Basic Books, New York.

Inglehart, R; Welzel, C. (2010) Changing Mass Priorities: the link between modernization and democracy. Reflections; vol.8, No. 2.

Jacobs, L.R; Shapiro, R.Y. (2002) Politics and Policymaking in the Real World - crafted talk and the loss of democratic responsiveness in: Jef, Manza; Fay L. Cook; Benjamin I. Page, (eds.), Navigating Public Opinion: polls, policy and the future of American democracy. Oxford University Press. 
$\mathrm{Ku}, \mathrm{H}$; Zussman, A. (2010) Lingua Franca: The role of English in international trade. Journal of Economic Behavior \& Organization, vol.75.

Linders, G.J.M. (2006) Intangible Barriers to Trade: the impact of institutions, culture and distance on patterns of trade. Doctoral Thesis, VU University, Amsterdam.

Madison, J. (1787) Federalist Fourteen in: Hamilton, A; Madison, J; Jay, J. The Federalist. J.R.Pole, (Eds); Hackett Publishing Company, Inc. Indianapolis/Cambridge, 2005.

Manza, J; Cook, F. L; Page, B. I. (2002) Navigating Public Opinion: polls, policy and the future of American democracy. Oxford University Press.

O'Rourke, K. H; Sinnott, R; Richardson, J. D; Rodrik, D. (2001). The Determinants of Individual Trade Policy Preferences: International survey evidence. Brookings Institution Press.

Pateman, C. (2003) Participation and Democratic Theory in: Robert A. Dahl; Ian Shapiro and Jose Antonio Cheibub, (Eds.) The Democracy Sourcebook. Massachusetts Institute of Technology.

Ruggie, J. G. (2004) Reconstituting the Global Public Domain - Issues, Actors, and Practices. European Journal of International Relations. SAGE Publications and ECPREuropean Consortium for Political Research, Vol. 10(4): 499-531

Shapiro, R Y. (2011) Public Opinion and American Democracy. Public Opinion Quarterly, Vol. 75, No. 5.

Shen, F. Edwards, H. H. (2005). Economic Individualism, Humanitarianism, and Welfare Reform: A Value-Based Account of Framing Effects. Journal of Communication, 55(4), 795-809.

Van Bergeijk, P.A.G; Brakman, S. (2010) The Gravity Model in International Trade: advances and applications. Cambridge University Press, U.K.

Van Ginneken, J. (2003) Collective Behavior and Public Opinion: rapid shifts in opinion and communication. Lawrence Earlbaum Associates Publishers, New Jersey.

Wendt, A. (1999) Social Theory of International Politics; Cambridge University Press.

Wonnacott, P; Lutz, M. (1989) Is There a Case for Free Trade Areas? in: Schott, J.J.(Ed.) Free Trade Areas and U.S. Trade Policy, pp. 59-84. Institute for International Economics, Washington, D.C. 


\title{
The Impact of Cultural Proximity on Public Opinion about Trade Partners: evidence from an experimental survey
}

\begin{abstract}
The use of experimental methods in International Relations (I.R.) studies continues to be relatively unpopular, and especially so among the International Political Economy (IPE) research fraternity in Brazil. Notwithstanding, this paper is the product of an experimental survey administered among the undergraduate students' population at the University of São Paulo in April 2014, in which the hypothesis that cultural proximity mattered to public opinion about trade partners was investigated and subsequently validated. In pretreatment tests, language, religion and social norms and values were identified as proxies for cultural proximity. These were incorporated into four treatment vignettes that described a potential trade partnership in terms of its economic gains as well as the cultural (dis)similarity of the partner country. With the addition of a control condition - having no economic or cultural information - the five vignettes were embedded into questionnaires administered to 503 students across 7 faculties. Treatment effects under all conditions confirmed that people's decisions were affected by the cultural indicators. Their contradictory response to descriptive questions however, implies that though their actions may be conducive with culturally influence, people's declarations will tend to suggest otherwise
\end{abstract}

Keywords: cultural proximity, public opinion, international trade

Resumo: A utilização de métodos experimentais em estudos de Relações Internacionais (RI) continua sendo relativamente incomum particularmente, entre os pesquisadores de Economia Política Internacional (EPI) no Brasil. Não obstante, este trabalho foi o resultado de um survey experimental aplicado entre os alunos de graduação da Universidade de São Paulo em abril de 2014, cuja hipótese de que a proximidade cultural importava para a opinião pública no que tange os parceiros comerciais foi investigada e, posteriormente validada. Nos testes de pré-tratamento, a língua, a religião e as normas e os valores sociais foram identificados como os indicadores para a proximidade cultural. Estes indicadores foram incorporados em quatro vinhetas de tratamento, em que uma parceria comercial foi descrita em termos dos ganhos econômicos, bem como a (não) similaridade cultural do país parceiro. Com a adição de uma condição de controle - em que não havia nenhuma informação econômica ou cultural - as cinco vinhetas foram incluídas em questionários aplicados a 503 estudantes entre 7 faculdades. Havia efeitos do tratamento em todas as condições e, portanto, foi possível confirmar que as decisões das pessoas foram afetadas pelos indicadores culturais. No entanto, as respostas contraditórias às questões descritivas sugeriram que por mais que as ações do público tendem a demonstrar coerência com a influência de atributos culturais, suas declarações verbais tendem a apontar ao contrário.

Palavras chaves: proximidade cultural, opinião pública, comércio internacional. 


\section{INTRODUCTION}

Scholars such as, Geert Hofstede, Samuel Huntington and Ronald Inglehart have contributed to culture's prominence in social science research through their studies in comparative cross cultural studies (Hofstede, 1980; Hofstede et.al, 1997; 2010) and the classification and distinction of societies based on cultural parameters (Huntington, 1996; Inglehart, 1990, 2000). In the ongoing debate about the influence of cultural attributes on the public's attitude towards issues of economic development, trade, domestic policies, etc. (Harrison \& Huntington, 2000) recalls that from the 1940s and 1950s,

much attention was paid to culture as a crucial element in understanding societies, analyzing differences among them and explaining their economic and political development (Harrision, L.E \& Huntington, S; 2000)

The adaptation of experimental methods to International Relations studies continues to be relatively unpopular among the international political economy (IPE) research community in Brazil. Notwithstanding, previous studies have alluded to the efficiency of such methods in the analysis of multidimensional choices such as those required in the preference of a trade partner (Umaña, Spilker \& Bernauer; 2014). Utilizing a survey experiment methodology, this research quantitatively assesses the extent to which the perception of cultural proximity influences public opinion about international trade partners ${ }^{1}$. By so doing, it will contribute to the consolidation of quantitative, large $\mathrm{N}$ experimental methodologies in I.R. studies as well as complement the body of literature that relates to public opinion and preferences in matters of international trade.

In Inglehart (1990) the author adopts Barnes' (1986) definition of culture as "a set of beliefs and assumptions developed by a given group in its efforts to cope with the problems of external adaptation and internal integration”. Huntington (2000) classifies culture 'in purely subjective terms' defining same as "the values, attitudes, beliefs, orientations, and underlying assumptions prevalent among people in a society". In light of the coherency among these authors' delineation of culture, said characterization will be adopted as the premise upon which the term culture is used throughout this paper.

\footnotetext{
${ }^{1}$ The terms 'cultural proximity' and 'cultural (dis)similarity' are considered synonymous and are used interchangeably throughout the paper.
} 
Thus, the term culture will refer to those beliefs and/or directives that orient the day to day attitudes, choices and behavior of a people.

As it relates to comparative studies of national cultures, Hofstede (1980) suggests that "cultures are not individuals: they are wholes, and their internal logic cannot be understood in the terms used for the personality dynamics of individuals" ${ }^{2}$. To this end, Hofstede makes the case for 'cultural dimensions' as the appropriate measure for performing comparative analyses between cultures. The basis for this recommendation comes from Hofstede's belief that "values more than practices are the stable element in culture"3. Based on this thesis therefore, the dominant value orientations of a given culture and consequently their proximity to that of another, may be determined by evaluating five 'universal' cultural dimensions, namely: power distance; collectivism versus individualism; femininity versus masculinity; uncertainty avoidance, and longterm versus short-term orientation.

The matter at hand however is the public's perception of cultural proximity and the consequent repercussions this has in their choices, preferences and opinions. Felbermayr \& Toubal (2007) address this issue by proposing a measure of cultural proximity that is based on visible / tangible cultural attributes which facilitate the identification with, or differentiation from, another's culture. For Felbermayr \& Toubal (2007) therefore, cultural proximity is derived from "the degree of affinity, sympathy, or even solidarity, between two countries [...] driven by the feeling of sharing a common identity and of belonging to the same group". As such, these authors suggest that a measure of cultural proximity may be ascertained through the use of proxies, such as; common language, religion, history, ethnicity and genetic traits.

The approach taken by Felbermayr \& Toubal (2007) favors the definition of cultural proximity as a closeness or resemblance in attributes of one culture to another. For an attribute such as the Portuguese language for example, a measure of cultural proximity would surpass Portuguese speaking countries to encompass countries who speak Latin derived romance languages such as Spanish, since they are derived from the same root language.

\footnotetext{
2 Hofstede, G. (1980) Culture's Consequences: international differences in work - related values. SAGE Publications

${ }^{3}$ Hofstede, G. (1980) Culture's Consequences: international differences in work - related values. SAGE Publications
} 
Notwithstanding, a measure of cultural proximity based solely on the merits of one cultural attribute creates room for inaccuracies. Therefore, in this research cultural proximity will be represented by an affinity among three (3) cultural characteristics, namely: language, religion and social norms and values.

Given that the experiment will be conducted among the Brazilian public, proximity in language will extend to the Latin derived romance languages; religion will refer to the religious expression predominantly practiced in Brazil - Roman Catholicism; and social norms and values will encompass those characteristics (attitudes, behaviors) that orient public conduct, cue interpersonal relations and determine social priorities.

The main hypothesis proposed in this research is that culture matters for the public and as such, public preference and opinion about trade partners is influenced by the cultural (dis)similarity with a partner country. In other words, people will tend to prefer trade with a partner country that shares their cultural orientations, though this preference may be contingent on the economic gain.

Based on previous research on the effects of framing on public opinion (Price, et al., 1997; Chong \& Druckman, 2007) and the assertions that "framing effects constitute one of the most stunning and influential demonstrations of irrationality" (Druckman; 2004) and that individuals tend to favor frames that are consistent with their values (Sniderman \& Theriault; 2004), four treatment vignettes were elaborated so as to describe a potential trade partnership in terms of the economic gains as well as the cultural (dis)similarity of the partner country. With the addition of a control condition having no economic or cultural information - the five vignettes were embedded into questionnaires that were administered to 503 undergraduate students from 7 faculties of the University of São Paulo. This approach facilitated making accurate analyses and inferences regarding the extent and circumstances under which having a culturally (dis)similar trade partner affected public opinion.

Effects were observed across all the treatment conditions which substantiated the hypothesis that culture matters to public preference for trade partners. The design of the questionnaire also made it possible to explore other behavioral traits of the public such as, people's susceptibility to cultural treatments in light of their pretreatment exposure 
to information about international trade and the difference in public response when reacting to objective 'treatment' questions versus providing descriptive answers to open ended ones.

Though previous research justify the external validity of both survey experiments (Barabas and Jerit; 2010) as well as the use of student samples in such experiments (Druckman and Kam; 2011), making generalizations about how preferences in the wider society would be affected by cultural proximity must be constrained. This is due to the distinctiveness of the social standing of the participating students' population and the inherent limitations in assessing how variations in these socio-economic contexts would impact public opinion about trade partners.

\section{SURVEY DESIGN}

The experiment was divided into two stages: 1) a pretreatment / exploratory survey for the determination of the proxies for cultural proximity; 2) the experimental opinion survey, in which the proxies determined in the exploratory survey were used as the treatment conditions for cultural (dis)similarity. Both stages of the survey were concluded within a 3 week period which minimized the possibility of change in environmental conditions affecting the respondent's mindsets.

\section{Pre-treatment survey}

There are several canteen facilities across USP's São Paulo campus, however, the meal ticket required to access these facilities can only be purchased at one central location. Given the agglomeration of students from varied departments and courses on any given day, it was considered the most strategic location for the administration of the pretreatment questionnaire. Armed with a predetermined sample size of $100^{4}$ and employing a non-probability purposive sampling strategy, undergraduate students waiting in line were invited to participate. Those who accepted received a one page questionnaire $^{5}$ comprised of two questions and a brief socio-demographic information section. The first question presented a list from which respondents were to choose and rank the five (5) indicators they regarded as most important in determining cultural

\footnotetext{
$4 \frac{1}{5}$ the sample size of the survey experiment $(\mathrm{N}=500)$ which was previously calculated via power analysis using survey pilot data ${ }^{5}$ See appendix $A$
} 
proximity between countries ${ }^{6}$, while the second asked respondents to name 3 countries they considered to be culturally similar to Brazil. To avoid any possibility of repetitions or spillover effects the pretreatment survey was concluded on the same day.

Based on the frequency with which respondents attributed highest or second highest priority to each indicator, the three highest ranked indicators for cultural proximity were: language (54\%), social norms and values (43\%), and religious practices and beliefs (28\%). Table 1 (below) summarizes the results from the first of the two questions found in the pre-treatment survey.

Table $1 \quad$ Pre-treatment Survey-Indicators of Cultural Proximity

\begin{tabular}{|c|c|c|c|c|c|c|c|c|c|c|c|}
\hline & $\begin{array}{l}\text { Colonial } \\
\text { History }\end{array}$ & $\begin{array}{c}\text { Natural } \\
\text { Resources }\end{array}$ & Language & $\begin{array}{c}\text { System of } \\
\text { governance }\end{array}$ & $\begin{array}{c}\text { Physical } \\
\text { Appearance }\end{array}$ & $\begin{array}{l}\text { Geographical } \\
\text { proximity }\end{array}$ & $\begin{array}{c}\text { Types of } \\
\text { industries }\end{array}$ & $\begin{array}{c}\text { Culinary } \\
\text { practices \& } \\
\text { preferences }\end{array}$ & $\begin{array}{l}\text { Religious } \\
\text { beliefs \& } \\
\text { practices }\end{array}$ & $\begin{array}{l}\text { National } \\
\text { Folklore }\end{array}$ & $\begin{array}{c}\text { Social } \\
\text { norms } \\
\& \\
\text { values }\end{array}$ \\
\hline Average & 4.33 & 5.66 & 2.71 & 4.88 & 5.71 & 5.01 & 5.7 & 5.32 & 3.91 & 4.76 & 2.99 \\
\hline Freq. \#1 & 5 & 2 & 36 & 2 & 2 & 6 & 1 & 2 & 8 & 6 & 30 \\
\hline Freq. \#2 & 12 & 1 & 18 & 13 & 1 & 8 & 2 & 4 & 20 & 7 & 13 \\
\hline Sum $1 \& 2$ & 17 & 3 & 54 & 15 & 3 & 14 & 3 & 6 & 28 & 13 & 43 \\
\hline
\end{tabular}

In response to the second pre-treatment survey question, a total of 25 countries were identified as being culturally similar to Brazil. The 3 most frequently cited were: Portugal (57\% of respondents), Argentina (51\% of respondents) and Angola (30\% of respondents). The country frequency data are summarized in graph 1 (below)

\section{Graph 1 Countries Culturally Similar to Brazil (pre-treatment survey)}

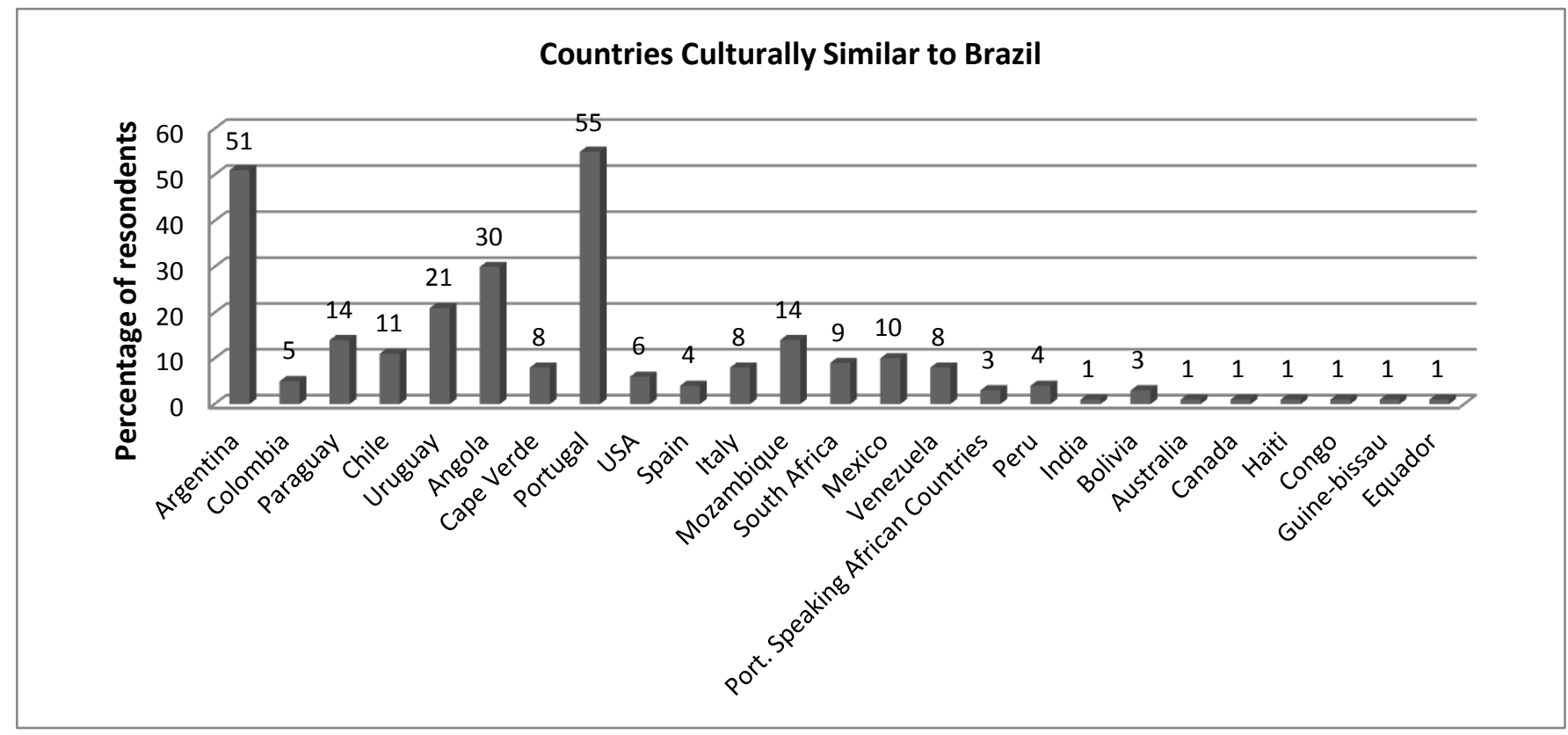


The results obtained in this pretreatment survey present a noteworthy coherency between the previously examined cultural proximity indicators and the countries cited as being most culturally similar to Brazil. This is evidenced by the semblance in language origin (all three utilize Latin derived Romance languages), the predominance of Roman Catholicism, and a shared history of Spanish / Portuguese colonization which still orients quotidian attitudes, behaviors and value orientations. It is on this basis of this coherency that these indicators were adopted as the proxies for cultural (dis)similarity in the treatment conditions.

\section{Experimental Survey - Design}

USP's São Paulo campus is composed of 29 faculties. To attain the predetermined sample size of 500 students, a multi staged equal probability sampling strategy was employed. Firstly, a random sequence of the 29 faculties was generated using a computerized random number generator. Subsequently, a cluster sampling technique was applied in which $10 \%$ of the undergraduate students' population from each faculty (as they appeared in the randomized order) was calculated to a sum of 500 students. To ensure comparative sample sizes across all the participating schools a minimum threshold of 40 students was established. This resulted in 7 schools being contemplated and total sample size of 503 students. $^{7}$

The second stage of probability sampling sought to identify those students who would participate in the survey. Based on the list of course offerings for the semestre corresponding to the survey administration ${ }^{8}$, a computerized random number generator was used to create a random sequence of the classes being offered to the undergraduate students' population of each department. This random sequence of classes was then utilized as the survey administration guide throughout each school. Notwithstanding, final confirmation of classes actually sampled was determined by the students' willingness to participate and the concurrence of the presiding professor.

While a more detailed analysis of the background covariates will be presented in a subsequent section of the paper, a brief statistical description of the student sample is as follows: $74 \%$ were female, $25 \%$ were male and $1 \%$ gave no response to the question of

\footnotetext{
${ }^{7}$ The 7 faculties from which samples were contemplated: Institute of Astronomy, geophysics and atmospheric sciences (41); School of Nursing (42); Faculty of Public Health (56); School of Communication and Art (109); Institute of Biomedical Sciences (41); Faculty of Education (85); Faculty of Architecture and Urbanism (129).

${ }^{8}$ First semestre of the 2014 academic year
} 
gender. In relation to the survey sample size of 503 students a majority of the students (26\%) were from the Faculty of Architecture and Urbanism, which were seconded by the School of Communication and Art $(22 \%)^{9}$. Participants from the other faculties selected corresponded to $17 \%$ (Faculty of Education), 11\% (Faculty of Public Health) and $8 \%$ from the Institute of Astronomy, geophysics and atmospheric sciences; School of Nursing and the Institute of Biomedical Sciences respectively. 33\% of the respondents described their political views as liberal, $61 \%$ as moderate and $4 \%$ as conservative. $^{10}$

\section{Experimental Survey - Method}

Respondents were randomly assigned to one of five conditions, four of which were treatment groups in which a potential trade partnership was framed as providing relatively high versus relatively low economic gains for Brazil and the partnering country was either culturally similar or culturally dissimilar to Brazil. Those in the control group were informed of a potential trade partnership with Brazil but received no additional background information.

Besides its experimental objective, the questionnaire contemplated three other outcome measure questions that sought to capture: a) the reasons to support government's choice of a potential trade partner; b) causes for non-support of a potential trade partner; and c) factors that promote support for trade with a potential partner.

The first section of the questionnaire was comprised of eight questions and included a pre-treatment question in which participants were asked to rate the frequency with which they were exposed to information about international trade ${ }^{11}$, followed by a vignette within which was embedded either the treatment or control frames ${ }^{12}$. The vignettes were all comparable in length and writing styles and were presented as extracts from a media publication. Prior to their distribution, the sequential order of the questionnaire was randomized with the use of computerized random number generator.

\footnotetext{
${ }^{9}$ Given its significantly large students' population in relation to the other schools only $5 \%$ of the total school population was included in the survey.

${ }^{10}$ As it so happens, none of the schools that were raffled were previously included in the pilot. This drastically reduced the likelihood of student's having repeated participations in both the pilot as well as the experiment.

${ }^{11}$ Respondents rated their exposition to international trade information via Radio, television, internet and newspaper

12 See appendix B
} 
Immediately after reading the vignette, respondents were asked if they would support the Brazilian government's decision to establish a trade partnership with the country described in the extract they had read. This was the 'treatment question' and the respondents' trade partner preference was measured on the basis of their decision to support / not support trade with the described partner.

The first two outcome measure questions were both descriptive and appeared on the first half of the questionnaire. In the first, respondents were asked to justify their decision in the treatment question and in the second to suggest three (3) characteristics of a country that would cause them to not support same as a trade partner. These two outcome measure questions were separated by enquiries about the respondent's background as it related to their "cosmopolitanism" via their international travel and prolonged residence overseas.

In exchange for the first half of the questionnaire respondents receive a second page ${ }^{13}$ which began with a manipulation check question (assigned solely to those respondents in the treatment groups). As a means of comparatively evaluating the weight attributed to the proxies of the determining variable (cultural proximity) a third outcome measure question instructed respondents to select and subsequently rank 5 variables from a list of 9 by the importance these factors have in the consideration of a potential partner country. The 9 variables ranged from social-cultural to economic and political characteristics attributes.

To minimize the risk of respondents' rating higher or lower the variables based on the order in which they were listed, same were randomized in six different distributions, which resulted in there being six different versions of this question ${ }^{14}$. Finally, respondents were asked to provide socio-economic, socio-demographic and background information, namely: age, religious affiliation, gender, course and period of study at the university.

\footnotetext{
${ }^{13}$ The questionnaire pages were numbered in advance to facilitate identification and exchange. Respondents were not made aware of this system of numeration.

${ }^{14}$ For the control group the randomization resulted in having 2 versions for this question
} 
Figure 1: Survey Design - Summary
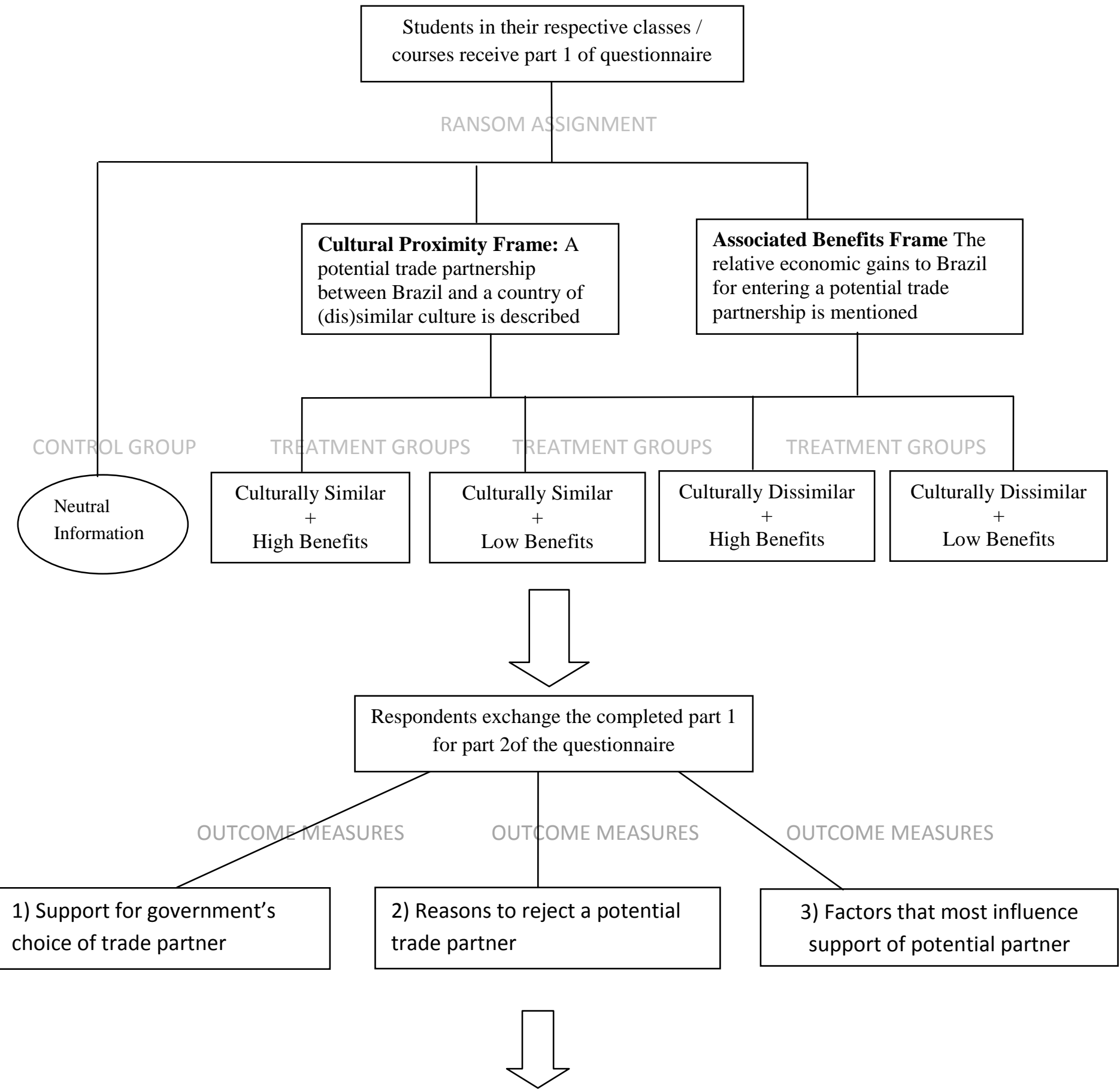

International Trade Partner Preference 


\section{EMPIRICAL RESULTS}

\section{ROBUSTNESS \& HOMOGENEITY}

In order to accurately estimate the causal effects of the treatments used in the experiment it was necessary to identify and discuss those factors that have the potential of provoking spurious results. Hence, a preliminary analysis to determine incidences of noncompliance and non-response, real-world pretreatment effects, and randomization of background covariates was conducted in order to confirm homogeneous treatment effects among subjects and across treatment groups.

\section{a) Non-compliance \& Non-Response}

The reliance on human subjects in political science experiments often generates noncompliance and / or non-response that escape the control of the researcher. Though the problem of missing data is curtailed by random assignment (Gerber and Green, 2012) in such instances a simple difference of means would no longer produce accurate treatment causal effect estimates given the non random nature of the missing data. ${ }^{15}$

Green \& Gerber (2012) define non-compliance when a subject receives the treatment for a condition other than that which he/she was assigned. Survey experiments however require a more nuanced contextualization of noncompliance given that the treatment received is oftentimes a result of the choices respondents make after receiving specific instructions. In this regard, when used in an experimental design surveys provide a pliable structure upon which different strategies may be implemented for identifying noncompliance. Horiuchi; et.al (2007) for example determined noncompliance as a measure of whether subjects opted to not visit a designated website after they were instructed to do so.

In this research, a manipulation check question was used to determine whether or not respondents had in fact absorbed the information in their assigned treatment condition. This objective question, which required subjects to recall the economic gains to Brazil as stated in the vignette they had previously read, was the first question on the second half of the questionnaire ${ }^{16}$. Compliant respondents were considered to be those who correctly answered this manipulation check question given their assigned treatment

\footnotetext{
${ }^{15}$ Horiuchi; et.al (2007) Designing and Analyzing Randomized Experiments: application to a Japanese election survey experiment.

${ }^{16}$ Respondents were not restricted in their contact time with the vignette found in the first part of the questionnaire. The manipulation check question was only given to respondents assigned to treatment groups and was only viewed upon submission of the first page of the questionnaire.
} 
condition. Table 2 (below) reports the average compliance evidenced across the four treatment groups.

Table 2

Compliance Among Respondents Given Treatment Assigned

$\begin{array}{cccc} & \text { High Econ Gains } & \text { Low Econ Gains } & \text { Total } \\ \text { Cult. Similar } & 55^{101} & 85^{101} & 140 \\ & (20 \%) & (31 \%) & (51 \%) \\ \text { Cult Dissimilar } & 60^{101} & 77^{100} & 137 \\ & (22 \%) & (28 \%) & (49 \%) \\ \text { Total } & 115 & 162 & 277\end{array}$

Note: Entries are numbers of compliant respondents. Values as a percentage of total compliant population are in parentheses. Numbers in superscript indicate the cell sample size

Though the results indicate a marginal increase in compliance under the conditions of low economic gains, in relation to the overall population of compliant respondents the rates are comparable across the different treatment groups. This suggests that people in the similar culture condition were as likely to internalize the information as people in the dissimilar culture condition. Thus, there is no reason to suspect that there was bias from one of the treatments being easier to remember.

Non-response is considered by Horiushi; et.al.(2007) as the circumstances in which a respondents fails to provide an answer for the measure of the outcome variable. A similar strategy was applied in this research such that non-response was based on subjects not providing an answer to the outcome measure question of whether or not they would support the government's decision to pursue trade relations with the country identified in the vignette they had received. There were a mere 13 instances of nonresponse which corresponded to approximately $3 \%$ of the total population of 503 students.

The culturally dissimilar + low economic gains treatment condition presented the highest frequency of non-response having 6 such incidences. This was seconded by the control group having three (3) instances of non-response. Two of the remaining four cases were in the culturally similar + low economic gains condition while both of the 
treatment conditions having high economic gains presented one case of non-response each.

The disparity in the number instances of non-response under the conditions of low economic gains, (approximately 62\%) may suggest that respondents found it more challenging to decide whether or not to support trade partnership when framed as having low economic gains. Notwithstanding, these significantly few cases of nonresponse is also evidence that in general respondents across all the treatment groups encountered very little difficulty in answering this outcome measure question.

\section{b) Pretreatment Effects}

Though random assignment to treatment and control conditions ensures that subjects are identical across the treated and untreated groups, non-experimental pretreatment / realworld pretreatment may also impact subject behavior, susceptibility to experimental conditions and complicate the accurate interpretation of treatment effects (Gaines and Kuklinski, 2011). Within the context of this study elevated absorption of information related to international trade was considered a possible means of inciting pretreatment bias which could resultantly reduce sensitivity to the proposed cultural (dis)similarity treatments.

As previously mentioned, a pretreatment question that enquired about the frequency with which respondents were exposed to information about international trade preceded the treatment / control vignettes. In said question, respondents rated on a scale of everyday $(=1)$, once or twice per week $(=2)$, hardly ever $(=3)$ or never $(=4)$, their exposure to information on international trade via radio, television, newspaper and the internet. The average exposure of the respondents was subsequently used to guage the existence of real-world pretreatment bias among the survey population. The results for pretreatment exposure under the treated and untreated conditions are summarized in table 3 (below). 


\begin{tabular}{|c|c|c|c|c|c|c|}
\hline & \multirow[b]{2}{*}{ Minimum } & \multirow[b]{2}{*}{ Maximum } & \multicolumn{4}{|c|}{ Standard } \\
\hline Group & & & Mean & $\begin{array}{l}\text { Standard } \\
\text { Deviation }\end{array}$ & $\begin{array}{l}\text { Error of } \\
\text { Mean }\end{array}$ & Median \\
\hline \multicolumn{7}{|c|}{ 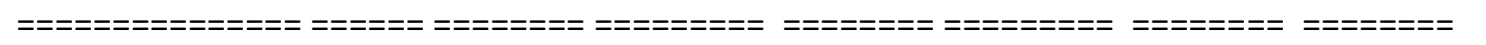 } \\
\hline T1 - Cult Sim + High Gains & 2.564 & 3.287 & 2.913 & 0.3368 & 0.1684 & 2.901 \\
\hline T2 - Cult Sim + Low Gains & 2.436 & 3.267 & 2.901 & 0.3913 & 0.1957 & 2.950 \\
\hline T3 - Cult Dissim+ High Gains & 2.614 & 3.277 & 2.970 & 0.3465 & 0.1732 & 2.995 \\
\hline T4 - Cult Dissim+Low Gains & 2.420 & 3.260 & 2.890 & 0.4162 & 0.2081 & 2.940 \\
\hline Control & 2.450 & 3.360 & 2.973 & 0.3942 & 0.1971 & 3.040 \\
\hline
\end{tabular}

The average exposure of among the participants across all treatment groups was comparable. The data suggests that prior to their participation in this survey respondents accessed information on international trade on average between once or twice per week $(=2)$ or hardly ever $(=3)$. Based on these results it is possible to confirm the noninfluence of real-world pretreatment bias on the estimated treatment effects.

\section{c) Randomization \& Covariate Balance}

To verify that the randomization process resulted in a balance of the background covariates across treatment groups, 2 multinomial logistic regressions ${ }^{17}$ were executed. The first, a null model with no indicators, and the second, a model with predictors for period and semestre of study, discipline, gender, age, religion, income, political ideology, and cosmopolitanism (ever travelled and/or lived abroad). The categories of treatment assignment defined the outcome variable in both models.

A subsequent likelihood ratio test failed to reject the null hypothesis that the two models were indistinguishable $(\mathrm{p}<0.967)^{18}$. This validates the randomization process and indicates that the background covariates were balanced across the treatment groups given there was no statistically significant difference between the null model and the alternate model (with predictors).

\footnotetext{
${ }^{17}$ See appendix C

${ }^{18}$ See appendix D
} 


\section{TREATMENT EFFECTS}

The potential outcomes model posits that the estimation of causal effect from treatment is the difference between the two potential states of the world in which on the one hand subjects receive treatment while on the other hand treatment is withheld. The average treatment effect could therefore be expressed as the average value of the potential outcome of all treated subjects minus the average value of the potential outcome of all untreated subjects (Gerber and Green, 2012). An accurate estimation of ATE relies on the random distribution of respondents into the treatment and control conditions and is also influenced by instances of noncompliance. Though all respondents were randomly assigned to treatment the occurrence of noncompliance, as previously mentioned, is suggestive that not all respondents in fact received their assigned treatment. Thus, analysis of treatment effects could only represent the intent-to-treat (ITT) and the average causal effect of treatment on the compliant (CACE) also known as the effects of treatment on the treated (TOT).

\section{Intention to Treat (ITT)}

Given the design of the experiment, a $2 \times 2$ cross cutting approach was utilized for analysis of the intent-to-treat effects (ITT) for the outcome variable of trade partner preference which was determined by respondent's support for the government's decision to pursue trade relations with a culturally (dis)similar country as identified in the treatment. Table 4 (below) summarizes of the ITT results for this outcome variable.

Table 4

Intent to Treat Effects Based on Assigned Treatment Conditions

\begin{tabular}{|l|c|c|}
\cline { 2 - 3 } \multicolumn{1}{c|}{} & High Economic Gains & Low Economic Gains \\
\hline Culturally Similar & $\begin{array}{c}80^{0.40} \\
(101)\end{array}$ & $\begin{array}{c}44^{0.50} \\
(101)\end{array}$ \\
\hline Culturally Dissimilar & $\begin{array}{c}67^{0.47} \\
(101)\end{array}$ & $\begin{array}{c}37^{0.49} \\
(100)\end{array}$ \\
\hline $\begin{array}{c}\text { Difference of Means } \\
\text { (ITT) }\end{array}$ & $13^{*}$ & $7^{* *}$ \\
\hline
\end{tabular}

Note: Entries are percentages. Cell sizes are in parentheses. Statistical significance: ${ }^{*} p<0.05 ;{ }^{*} p>0.05$; Numbers in superscript indicate the standard deviation. 
Treatment effects were observed under all four conditions. The most significant effects were observed under the conditions of high economic benefits to Brazil, which showed an $80 \%$ preference when the potential partner shared Brazil's cultural orientations and $67 \%$ on the contrary. When framed as providing relatively low economic benefits to Brazil a culturally similar trade partner continued to be preferred. This was evidenced by the $44 \%$ preference when the potential partner country was culturally similar as opposed to $37 \%$ when the partner was culturally dissimilar. These results suggest that contingent on economic benefits respondents prefer to trade with a culturally similar partner country.

Considering the hypothesis that no distinctive difference existed between the culturally similar and the culturally dissimilar framing of a potential trade partner, the results show that at $95 \%$ confidence interval a difference of means p-value of 0.324 fails to reject this hypothesis under conditions of low economic gains. Under conditions of high economic benefits however, a difference of means p-value of 0.037 rejects this hypothesis. Based on these results it may be inferred that when faced with the choice of a potential trade partner public opinion not only prefers conditions of favorable economic gains but also favors a trade partner country that shares in its cultural orientations.

Relative to receiving no cultural information respondents demonstrated preference for trade with partner country whose cultural information was divulged. As reflected in table 5 (below), more significant treatment effects were observed when cultural similarity information was received as opposed to when no cultural information was received.

Table 5 Intent to Treat Effects Relative to Receiving No Cultural Information

\begin{tabular}{|l|c|c|}
\cline { 2 - 3 } \multicolumn{1}{c|}{} & High Economic Gains & Low Economic Gains \\
\hline Culturally Similar & $80^{0.40}$ & $44^{0.50}$ \\
$(101)$ & $(101)$ \\
\hline Control & $24^{0.43}$ & $24^{0.43}$ \\
& $(100)$ & $(100)$ \\
\hline Difference of Means & $56^{*}$ & $20^{*}$ \\
\hline
\end{tabular}

Note: Entries are percentages. Cell sizes are in parentheses. Statistical significance: ${ }^{*} p<0.05 ;{ }^{*} p>0.05$; Numbers in superscript indicate the standard deviation 
The difference in mean effect between these two conditions corresponded to $56 \%$ under conditions of favorable economic gains ( $\mathrm{p}$-value: $<2.2 \mathrm{e}-16$ ), and $22 \%$ under conditions of low economic benefits ( $p$-value 0.0021 ). At $95 \%$ confidence interval the difference of means p-values under both economic conditions rejects the hypothesis that identifying a potential trade partner as being culturally similar has the same effect as receiving no cultural information.

As a measure of how differently subjects reacted to the culturally similar as opposed to the culturally dissimilar treatment conditions a comparison was made between the mean effects under each of these conditions and the mean effects when no cultural information was received (control condition). The results from these comparisons are presented in table 6 (below).

Table 6 Difference in Mean Effects Between Treatment and Control Conditions

\begin{tabular}{|l|c|c|}
\cline { 2 - 3 } \multicolumn{1}{c|}{} & High Economic Gains & Low Economic Gains \\
\hline Culturally Similar & $\begin{array}{l}56^{* 24} \\
(80)\end{array}$ & $\begin{array}{l}20^{* 24} \\
(44)\end{array}$ \\
\hline Culturally Dissimilar & $\begin{array}{l}43^{*} 24 \\
(67)\end{array}$ & $13^{*} 24$ \\
& $(37)$ \\
\hline
\end{tabular}

Note: Entries are percentages. Average treatment effects for cells are in parentheses. Statistical significance: ${ }^{*} p<0.05 ;{ }^{* *} p>0.05$; Superscript ${ }^{24}$ indicates the mean effect under the control condition

As previously demonstrated, the difference in means between the culturally similar and control conditions rejected the hypothesis of their indifference. A similar trend was observed upon comparing the average effects of the culturally dissimilar treatment with the untreated condition. The difference in mean effect between these two conditions corresponded to $43 \%$ under conditions of favorable economic gains (p-value: $1.703 \mathrm{e}-$ 10 ), and $13 \%$ under conditions of low economic benefits (p-value 0.043). At 95\% confidence interval the difference of means p-values under both economic conditions rejects the hypothesis that identifying a potential trade partner as being culturally dissimilar has the same effect as receiving no cultural information. Notwithstanding, as it relates to participants' reaction to either of the cultural treatments the results indicate that conditional on economic gains respondents were more responsive to the culturally similar treatment than to its counterpart. 


\section{Compliance Average Causal Effect (C.A.C.E.)}

Also known as the "treatment effect on the treated", the CACE is a treatment estimate for the subset of respondents regarded as compliant based on their confirmation of receiving the assigned treatment. Since CACE is a fraction of the intent-to-treat (ITT) its estimates are derived by dividing the ITT by the proportion of respondents in the treatment group who passed the manipulation checks minus the proportion of respondents in the control group who incorrectly answered the manipulation checks.

Since in the previous computation of the ITT effects the difference of means was derived from the proportion of supporters in the culturally similar group minus the proportion of supporters in the culturally dissimilar group, the estimation of the CACE will continue to consider cultural similarity as the treatment condition and cultural dissimilarity the control. Thus, CACE $=$ ITT $/$ (proportion of respondents in the culturally similar group who passed the manipulation checks) - (proportion of respondents in the culturally dissimilar group who incorrectly answered the manipulation checks). The CACE results are recorded in table 7 (below).

Table 7

Average Treatment Effects on the Treated (C.A.C.E)

\begin{tabular}{|l|c|c|}
\cline { 2 - 3 } \multicolumn{1}{c|}{} & High Economic Gains & Low Economic Gains \\
\hline Culturally Similar & $\begin{array}{c}55^{0.27} \\
(101)\end{array}$ & $\begin{array}{c}85^{0.42} \\
(101)\end{array}$ \\
\hline Culturally Dissimilar & $\begin{array}{c}60^{0.30} \\
(101)\end{array}$ & $\begin{array}{c}77^{0.38} \\
(100)\end{array}$ \\
\hline C.A.C.E ${ }^{19}$ & $35_{13}$ & $19_{7}$ \\
\hline
\end{tabular}

Note: Entries are the number of compliant respondents. Sample sizes are in parentheses. Numbers in superscript indicate the proportion of respondents in the treatment condition who were compliant. Numbers in subscript indicate the mean ITT. CACEs are percentages.

The CACE estimates reaffirm the results obtained in the mean ITTs and suggest that there were greater treatment effects when the cultural treatments were coupled with conditions of favorable economic benefits. This is confirmed by a CACE of $35 \%$ under conditions of high economic gains as opposed to $19 \%$ when economic gains were

${ }^{19}$ CACE $=$ ITT $/(0.69-0.32)=0.37$ 
framed as unfavorable. Based on these observations it may be inferred that both the CACE and the ITT estimates lend strong support to the hypothesis that cultural (dis)similarity does matter to public opinion as with regards to their preference for a trade partner. In addition the results indicate that contingent on economic gains public opinion favors trade with a culturally similar partner country.

\section{Background Covariates}

Questions aimed at capturing data on respondents' pretreatment conditions were included in both sections of the questionnaire, having five such questions in the first section and six in the second. In the first section, these background questions made enquiries about the respondent's political ideology, party identification and 'cosmopolitanism', while in the second, the focus was on socio-demographics. A complete discrimination of these results have been included in the appendices ${ }^{20}$, however a discussion of some noteworthy findings was deemed necessary.

In one of the background questions in the first part of the questionnaire respondents received a spectrum which ranged from -5 (extreme left) to +5 (extreme right), with zero corresponding to the centre, and were asked to indicate where on the spectrum best represented their ideological political views. Although there were significantly more females than males participating in the survey, the answers provided to this question indicated that a majority of the females (24\%) considered themselves to be at the centre while the greater portion of males $(7 \%)$ positioned themselves marginally to the left of centre, at the -2 position. (See graph 2 below)

\footnotetext{
${ }^{20}$ See appendix E - Descriptive Statistics on Background Covariates
} 


\section{Graph 2 Political Ideology Based on Gender}

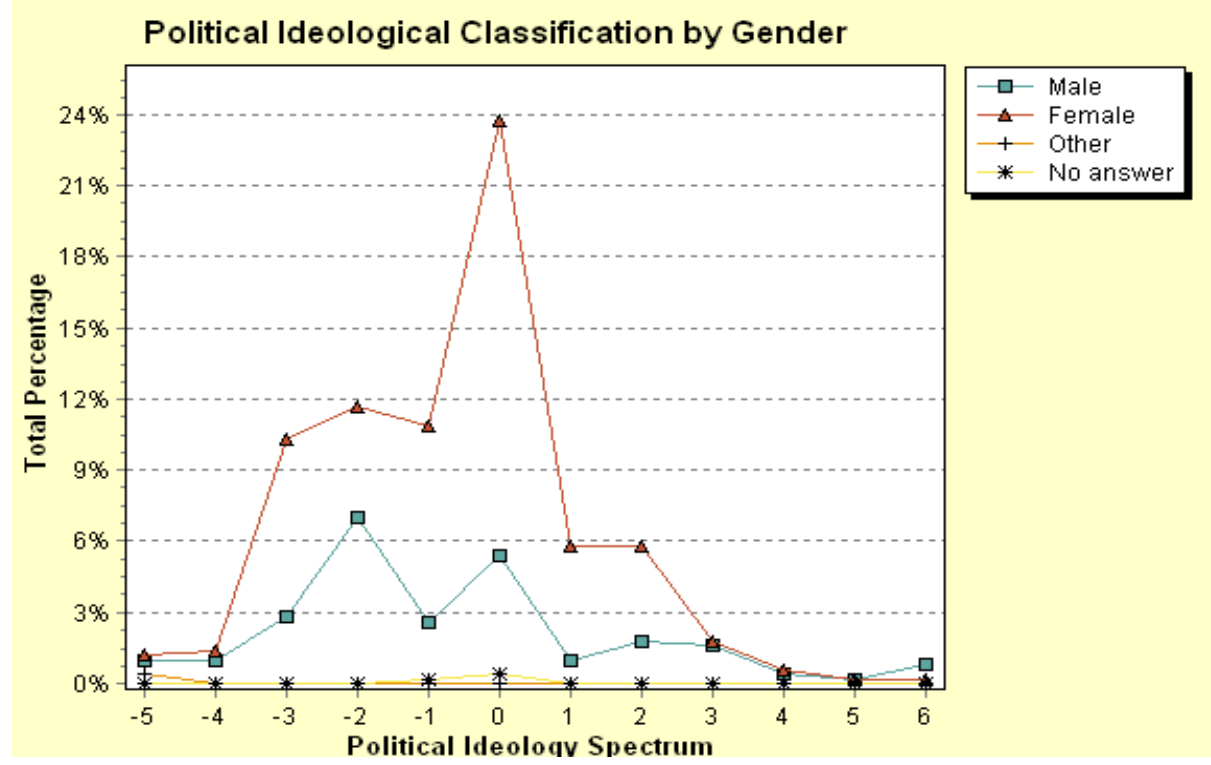

These findings were further reinforced with some degree of clarification in the answers provided to the subsequent question which required respondents to identify their political party of choice. The results from this question have been graphically displayed in graph 3 (below).

\section{Graph $3 \quad$ Preferred Political Party}

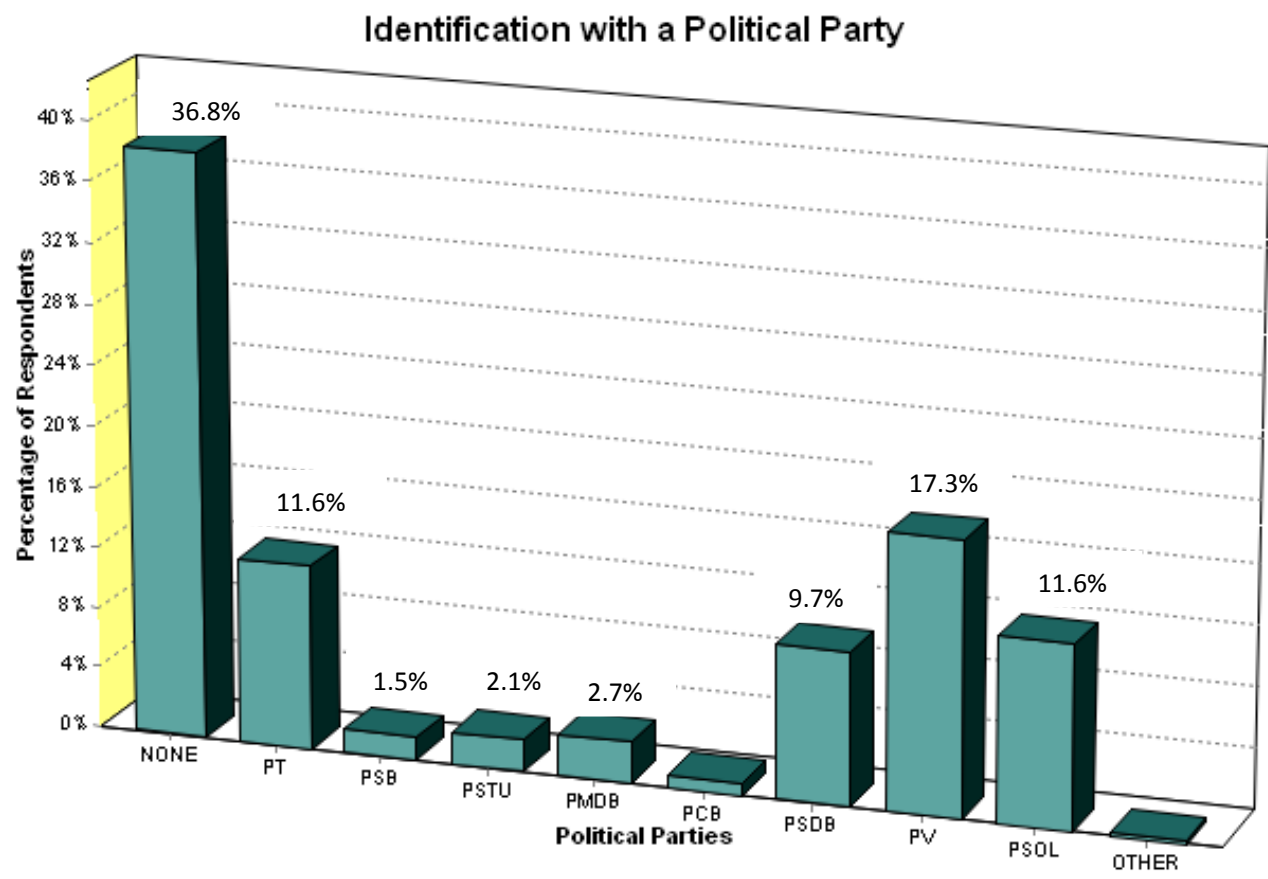


In Brazil's current political landscape, three of the four most frequently selected political parties (PT, PSDB and PV) are run on platforms of social-democracy coherent with philosophies of the centre-left. Corresponding to $11.6 \%$ of the respondents, the Socialist Freedom Party (PSOL) traditionally positioned more left of centre than the three previously mentioned parties, equals with the Workers' Party (PT) as the second most frequently selected option among the population. In consolidating the observations from the previously discussed political spectrum question therefore, (see graph 2 above) it may be inferred that the greater part of the participating students' population tended towards centre / centre-left political ideologies and the corresponding political parties.

While these inferences were reiterated even further by the answers provided to a question about the respondents' degree of conservatism (see appendix 3), an interesting pattern was observed when the declared degree of conservatism was correlated with monthly income ${ }^{21}$. (See graph 4, below).

\section{Graph $4 \quad$ Monthly Income in Relation to Degree of Conservatism}

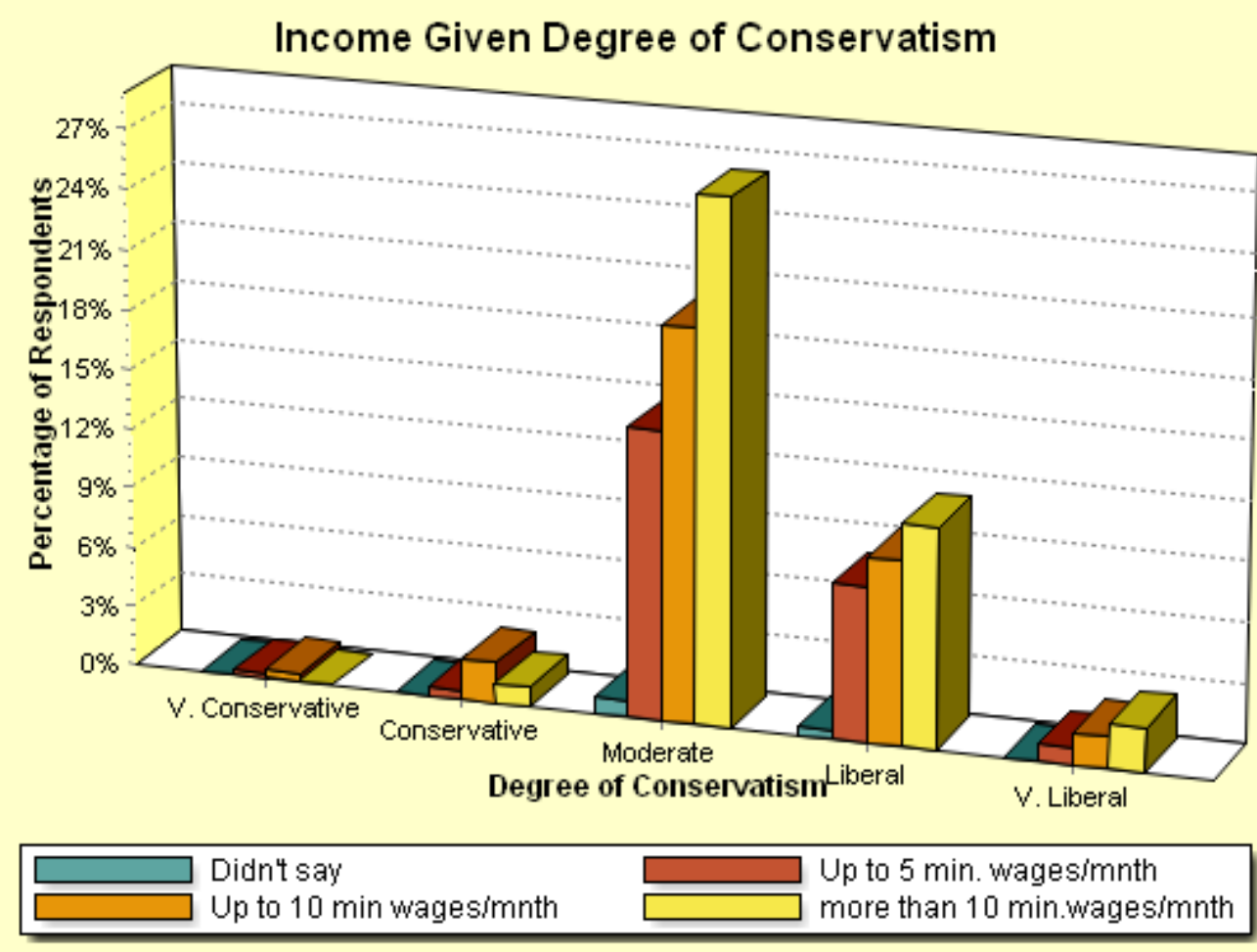

\footnotetext{
${ }^{21}$ Given that the participants were students they were asked to include in their estimates of monthly income all sources of income
} (autonomous, salaries and / or grants) that represented the averaged total of their family's earnings over the last 12 months. 
Although a majority of the respondents in all three income ranges classified themselves as moderates $(26.2 \%, 19.7 \%$ and $14.5 \%$ respectively) respondents within the highest income brackets consistently outnumbered their counterparts in the positions left of centre, with an inversion of this relation taking place on the right of centre. Thus, $13.3 \%$ of the highest income earners considered themselves liberals as compared to $10.9 \%$ in the middle income group and $8.6 \%$ among the lowest income earners. This pattern was however interrupted by the percentage of middle income earners who regarded themselves as conservatives doubling in number those from the highest income bracket.

Hence, while $2.4 \%$ of the respondents who reported a monthly income of up to ten minimum wages ${ }^{22}$ considered themselves conservatives, only $1 \%$ of those in the highest income bracket and $0.6 \%$ in the lowest income group professed being conservatives. Though detailed discussions of these findings go beyond the scope of this research, it is worth noting that this relation may be indicative of Brazil's budding middle class and their tendencies towards more conservative stances. Based on the data, it may be inferred that the members of the upper class are more liberal while those in the middle class have an inclination towards conservatism.

\section{Justification of Response to Treatment Question}

Immediately following the participant's response to the treatment question of whether or not they would support Brazil's establishment of a trade partnership with the country described in the vignette, an open ended question provided the means by which respondents could briefly explain the reason for their decision. By utilizing the qualitative data analysis (QDA) software WORDSTAT a cross-tabulation frequency analysis facilitated the identification of the most frequently cited terms and their association to the different treatment conditions. (See graph 5 below)

\footnotetext{
${ }^{22}$ Based on Brazil's national minimum wage of R\$724 per month
} 


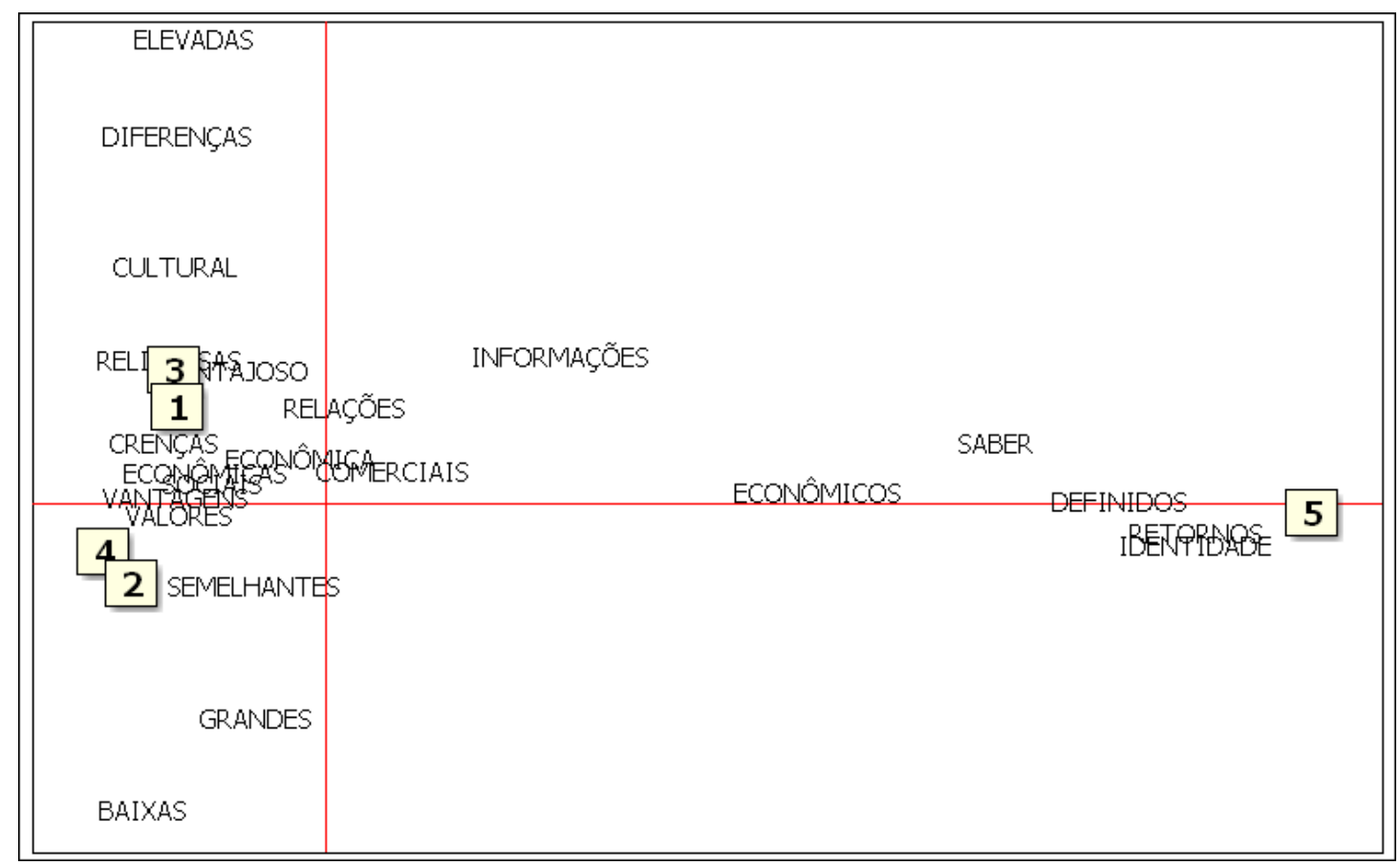

The close proximity of all four treatment conditions is cause to assume that the decision of whether or not to support trade with the described partner country was a direct result of the treatment effects. On the one hand, the proximity between pairs of treatment groups ( 1 and 3 in comparison to 2 and 4 ) is suggestive that respondent's decisions were primarily determined by the economic gains to Brazil, given that the underlying similarity in these group pairings was the way in which the trade partnership was framed, that is: 'high' (elevada) in groups 1 and 3 and 'low' (baixos) in groups 2 and 4. On the other hand however, the fact that terms such as 'advantage' (vantagem), 'economic' (econômica), beliefs (crenças), and values (valores) were so tightly interwoven and in close relation to all four treatment groups makes it possible to assume that (dis)similarity of the cultural proxies also created a basis for the decisions taken by the respondents.

Regarding the control group, the expressions used with most frequency in respondents' justifications revolved were: 'defined' (definidos), 'returns / gains' (retornos) and 'identity' (identidade). The repeated use of these terms to explain the response given to the 'treatment question' is consistent with the vignette received by the participants in this group, given that they were neither informed of the economic gains to Brazil nor the identifying characteristics of the potential partner country. This clear distinction 
between the words used by respondents in the control group as opposed to those in the treatment conditions further corroborates the assumption of the strong effects of the treatments over the respondents' opting for or against support and their reasons for doing so.

\section{Country Characteristics that Deter Public Support of Trade Partner Country}

With the aim of further scrutinizing the public's reasoning about international trade partnerships, a second open ended question gave respondents the opportunity of providing a brief description of country attributes that dissuade support for the establishment of a trade partnership agreement. This second outcome measure question therefore, sought to identify the characteristics associated with a country whose potential trade partnership with Brazil would not have public approval.

Again utilizing the WORDSTAT - QDA software, a keyword frequency analysis based on the word repetitions among the respondents was conducted. The words with the highest percentage of case occurrences ranged from, 'politics' (política) cited by $13 \%$ of the respondents to 'corruption' (corrupção) mentioned in $3.8 \%$ of the answers ${ }^{23}$. A list of the most frequently repeated words and the percentage of the population that used them is presented in graph 6 (below).

\section{Graph $6 \quad$ Country Attributes that Dissuade Public Approval of Trade Partnership}

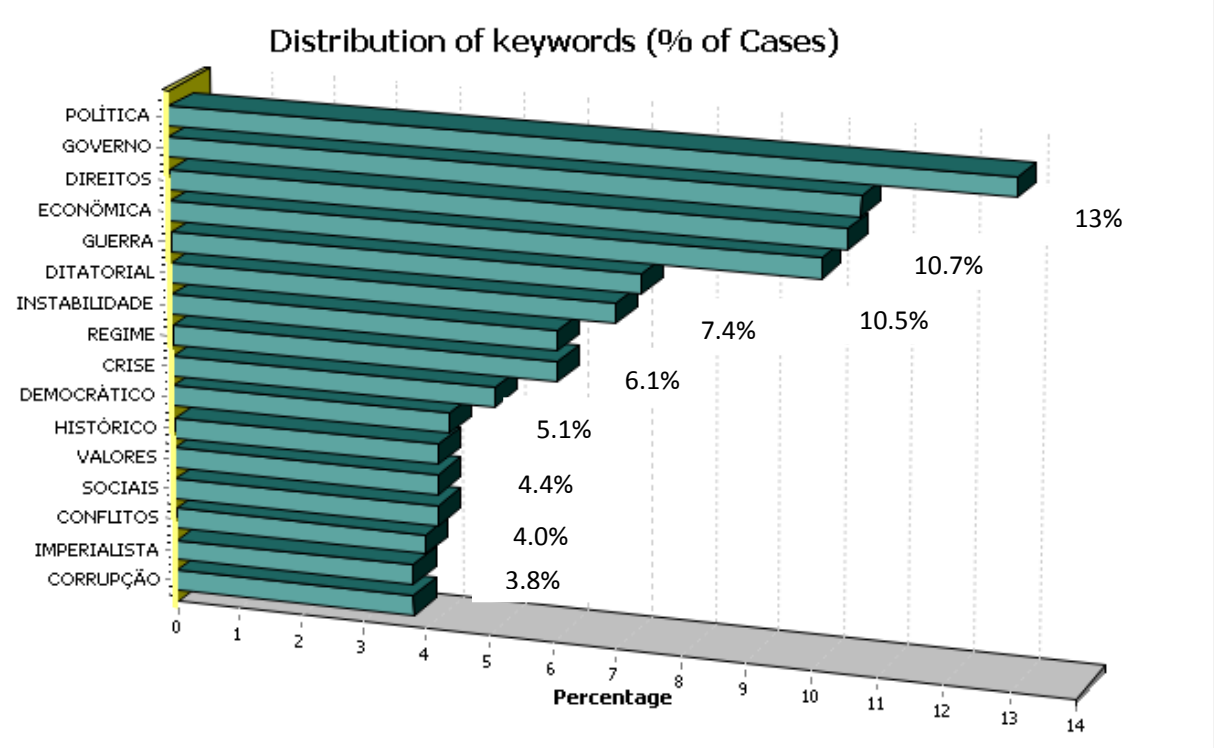

\footnotetext{
${ }^{23}$ The threshold used for this classification was a minimum 20 case occurrences / participant repetitions which corresponded to
} approximately $4 \%$ of the population 
The performance of a cluster analysis facilitated the identification of the main groupings in which these country characteristics may be classified. These categorizations are demonstrated in graph 7 (below) in which the words frequently utilized are positioned based on their relation to three major groupings - political, economic and socio-cultural characteristics. The words' sizes are representative of the frequency with which the words were repeated my respondents. These qualitative data analyses provides an additional basis for substantiating the claim that public opinion about a trade partnership is influenced not only by political and economic traits but also by the socio-cultural particularities of the partner country as well.

\section{Graph $7 \quad$ Cluster Analysis of Country Attributes that Dissuade Public Approval of Trade}

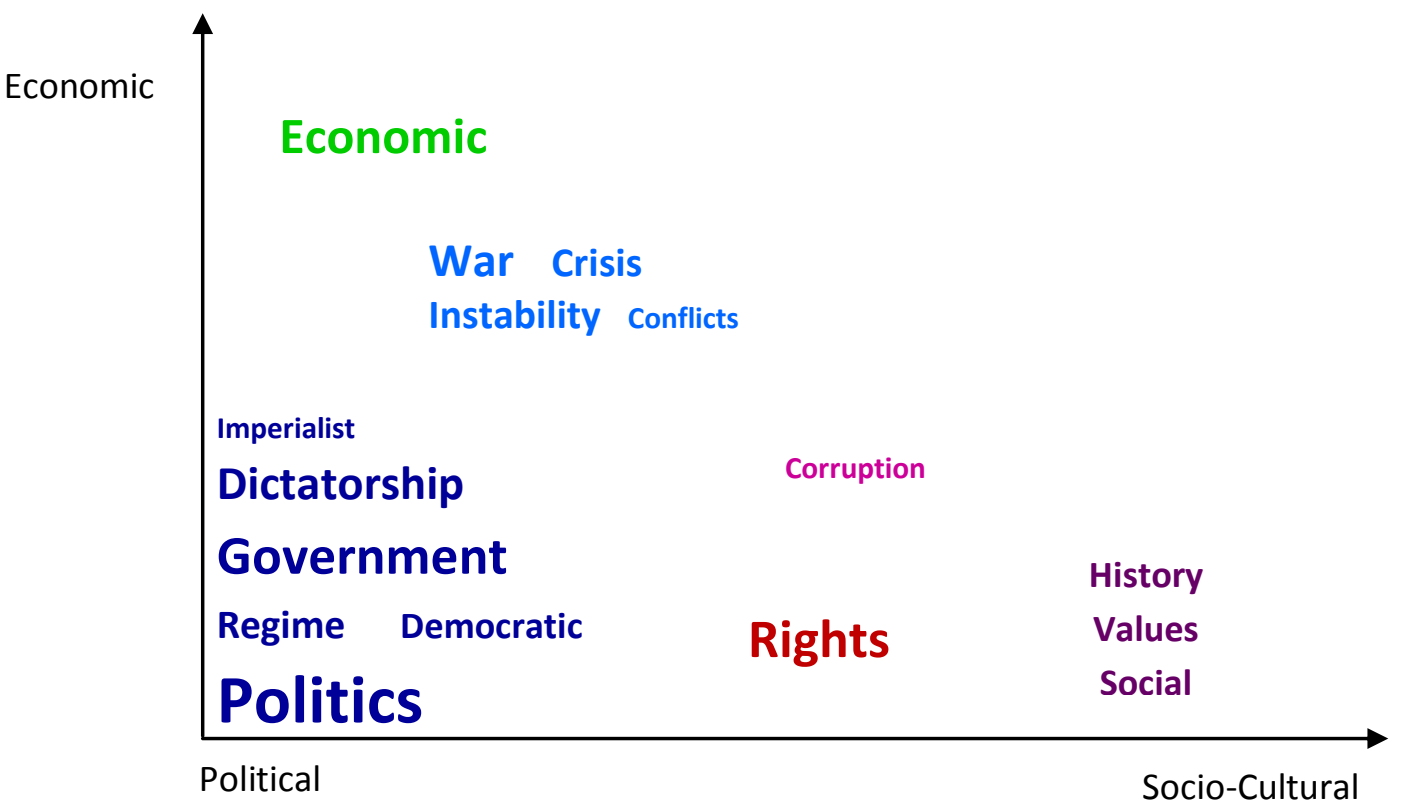

\section{Factors That Stimulate Public Support}

The hypothesis that public opinion about preferred trade partners is affected by the cultural (dis)similarity of the partner country was further examined in the second half of the questionnaire via a comparative ranking task. The objective of this measure was to determine how influential cultural proxies were when compared to other factors. Hence, respondents received a list of 9 variables and were asked to identify the five they considered indispensible when contemplating support of a potential trade partner country. Subsequently, the participants were asked to rank the five factors they had selected by means of the degree of influence each factor had in their decision to support 
trade with a particular country ${ }^{24}$. Graph 8 (below) displays the average frequency with which factors were ranked in the top three positions by the majority of participants.

Graph $8 \quad$ Highest Ranked Factors that Influence Public Opinion

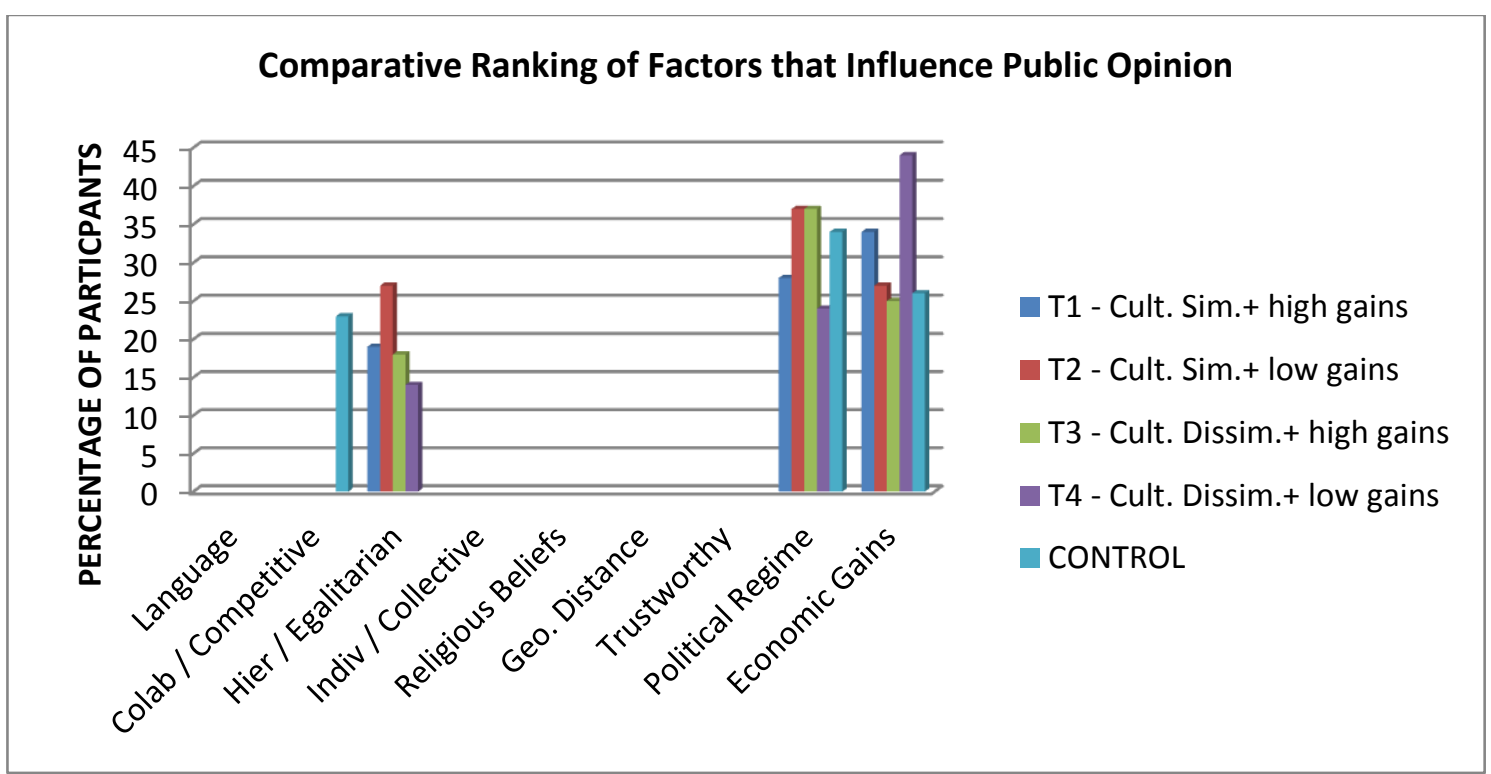

Consistently across all four treatment conditions respondents gave top priority to economic gains and political regime. Though oscillating between the positions of first and second, on average $64 \%$ of respondents across the treatment groups and $57 \%$ of the control, considered the political and economic traits of a country to be the most important attributes to be evaluated when opining about a potential trade partnership.

During the pilot stage of the experiment social norms and values as a proxy for cultural (dis)similarity was consistently classified as the most influential of the cultural proxies $^{25}$. Given the array of characteristics that are implied by 'social norms and values' a more detailed specification of this cultural proxy was adopted for the comparative ranking task in this experiment. Thus, of the 9 indicators from which participants had to choose and rank, 4 of them referred to dimensions of a country's social norms as values ${ }^{26}$. This reclassification of 'social norms and values' was derived

\footnotetext{
${ }^{24}$ The scale ranged from (1) most important to (5) least important and the ranking attributed to one indicator could not be repeated or equaled with the ranking given to of another.

${ }^{25}$ See appendix $\mathrm{F}$

${ }^{26}$ The four dimensions of social norms and values that were used in this task were: collaborative - competitive; hierarchicequalitarian; individualistic-collective; trustworthy.
} 
from the 'dimensions paradigm' proposed by Hofstede $(1980 ; 2010)$ and concept of 'terminal' and 'instrumental' values (Rokeach; 1973 apud Hofstede; 2010) ${ }^{27}$

Of the four dimensions that were used, the results indicate that a country being hierarchic / egalitarian was of more significance to public deliberations than all of the others. On average, $19.5 \%$ of the respondents from the treatment groups ranked hierarchy / equalitarianism as the highest regarded dimension of a country's social norms and values and also the third most important factor to be considered when evaluating a trade partner. For respondents in the control group however, third place consideration was given to a society's tendency toward collaboration / competitiveness, as indicated by $23 \%$ of those assigned to this group.

Though the factors associated with social norms and values were consistently ranked third in the classifications a noteworthy observation is that of the coherency of these results with the clusters discussed in the previous section, in which the causes for public rejection of a trade partner were identified. The results from this comparative ranking task therefore, reaffirm the hypothesis that though possessing less weight than the other variables, socio-cultural particularities do matter to the public deliberation of trade partners.

\section{DISCUSSION}

The results from this survey experiment clearly indicate that contingent on economic gains the public will prefer trade with a culturally similar country. That is to say, there is preference for a trade partner country with which there exists a feeling of shared identity and common values. However, the use of a convenience sample of undergraduate students, predominantly from the upper and middle classes, brings into question the external validity of these findings. Notwithstanding, the data provides solid evidence to substantiate the claim that cultural proximity does influence the way people think about trade partners and provides a premise for future replication among the general public.

\footnotetext{
${ }^{27}$ For Hofstede (2010), terminal values are those nouns that represent desired end states such as equality. Instrumental values are however described as adjectives that suggest the means of attaining the desired state, for example, honesty.
} 
Compared to other political and economic factors the cultural proxies were consistently outranked in their importance to the public's evaluation of a potential trade partner. By relying solely on these indicators therefore (see graph 8), it would appear that the cultural proxies (language, religion and social norms and values) were not particularly relevant to the public's thought process. The outcome from the experiment however, paints a different picture as the fact that there were treatment effects across all four treatment conditions (see table 4) was indicative of people behaving as though the cultural variables mattered.

This apparent contradiction in the data represents an invaluable outcome for this research, because it brings into discussion the difference between what people say versus how they act. While the answers given in the descriptive questions (what people had to say) attributed little importance to culture, the presence of treatment effects (how people reacted to cultural treatments) suggested otherwise. In addressing this issue Hofstede et.al (2010) makes the argument that inferring people's value oriented preferences from survey questions gives ambiguous results given that "people will not always act as the have scored on the questionnaire" (p.28). This therefore highlights the merits of this research and the value of its contributions. The use of an experimental methodology made it possible to not only to identify the previously mentioned behavioral contradiction but also to make more precise estimates about the influence of culture on public opinion.

These results have significant implications for the opinion-trade research agenda as far as having a better understanding of not only what people have to say about policy issues but more importantly how they react towards them. The use of experimental methods in International Relations (I.R.) studies continues to be relatively unpopular and especially so among the International Political Economy (IPE) research fraternity in Brazil. However, the analytical possibilities that the survey experiment afforded in this investigation of culture as a determining variable in public opinion about trade partner preferences, validates even more the continued application of these methods to other areas of I.R. research. 


\section{REFERENCES}

Barabas, J; Jerit, J. (2010). Are survey experiments externally valid? American Political Science Review, 104(02), 226-242.

Chong, D; Druckman, J. N. (2007) Framing Theory. Annual Review Political Science; vol. 10:103-26.

Druckman, J.N. (2004) Political Preference Formation: competition, deliberation, and the (ir) relevance of Framing Effects. American Political Science Review, vol. 98, No. 4.

Druckman, J. N; Kam, C. D. (2011). Students as experimental participants. Cambridge handbook of experimental political science, 41-57.

Felbermayr, G. J; Toubal, F. (2010). Cultural Proximity and Trade. European Economic Review, 54(2), 279-293.

Gaines, B. J; Kuklinski, J. H; Quirk, P. J. (2007). The logic of the survey experiment reexamined. Political Analysis, 15(1), 1-20.

Gerber, A. S.; Green, D. P. (2012) Field Experiments: design, analysis and interpretation. W.W. Norton, New York.

Horiuchi, Y., Imai, K., \& Taniguchi, N. (2007). Designing and Analyzing Randomized Experiments: application to a Japanese election survey experiment. American Journal of Political Science, Vol. 51, No. 3, p. 669-687

Harrison, L.E; Huntington, S.P; (2000) Culture Matters - how values shape human progress. Basic Books Publications, New York.

Hofstede, G. (1980) Culture's Consequences: international differences in work related values. SAGE Publications, Beverly Hills CA.

Hofstede, G; Hofstede, G.J; Minkov, M. (1997) Cultures and Organizations: software of the mind - intercultural cooperation and its importance for survival. $1^{\text {st }}$ edition, McGraw Hill, U.S.A.

Hofstede, G; Hofstede, G.J; Minkov, M. (2010) Cultures and Organizations: software of the mind - intercultural cooperation and its importance for survival. $3^{\text {rd }}$ edition, McGraw Hill, U.S.A.

Huntington, S. P. (1996). The clash of civilizations and the remaking of world order. Penguin Books, India.

Inglehart, R; (1990) Culture Shift in Advanced Industrial Society. Princeton University Press Publications. 
Inglehart, R. (2000) Culture and Democracy. In: Harrison, L. E; Huntington, S. P. (eds.), Culture Matters: How Values Shape Human Progress, Basic Books Publications, New York.

Price, V; David, T; Powers, E. (1997) Switching Trains of Thought: the impact of news frames on readers' cognitive responses. Communication Research, vol. 24: 481

Sniderman, P. M; Theriault, S. M. (2004). The Structure of Political Argument and the Logic of Issue Framing.In: Studies in Public Opinion, eds. Willem E. Saris and Paul M. Sniderman. Princeton, NJ: Princeton University Press, 133-65.

Umaña, V; Spilker, G; Bernauer, T. (2014) Selecting Partner Countries for Preferential Trade Agreements: experimental evidence from Costa Rica, Nicaragua, and Vietnam European Political Science Association (conference) 
Na tabela abaixo há 11 fatores que podem descrever proximidade cultural entre países.

1. Circule os números na coluna a esquerda da tabela que em sua opinião correspondem aos cinco (5) indicadores que são indispensáveis para a determinação de proximidade cultural entre países.

\begin{tabular}{|c|l|l|}
\hline 1 & História colonial & \\
\hline 2 & Recursos naturais & \\
\hline 3 & Língua & \\
\hline 4 & Sistema de governança & \\
\hline 5 & Aparência física dos nativos & \\
\hline 6 & Proximidade geográfica & \\
\hline 7 & Semelhança nos tipos de indústrias & \\
\hline 8 & Práticas e preferências culinárias & \\
\hline 9 & Crenças e práticas religiosas & \\
\hline 10 & Normas e valores sociais & \\
\hline 11 & Folclore nacional & \\
\hline
\end{tabular}

2. Na coluna à direita da tabela, ranquei de $\mathbf{1}=$ MAIS importante a $\mathbf{5}=$ MENOS importante, sem repetir ou empatar, os cinco (5) indicadores escolhidos, pela importãncia destes na determinação de proximidade cultural entre países.

3. Identifique 3 países que na sua opinião são culturalmente próximos ao Brasil?

a)

b)

c)

DADOS PESSOAIS (estas informações serão utilizadas somente para fins da pesquisa) Incluindo salários, atividades autônomas e quaisquer outras fontes de renda, o que era a renda familiar total combinado durante os últimos 12 meses? $\quad$ *salário mínimo $=R \$ 678 / \mathrm{mês}$

$\square R \$ 0$ - R\$4.100 (até 5 salários mínimos por mês)

$\square \mathrm{R} \$ 4.100$ - R\$8.140 (até 10 salários mínimos por mês)

$\square>R \$ 8.140$ (mais que 10 salários mínimos por mês)

Idade: $\square$ 17-19

$\square$ 20-24

$\square$ 25-29

$\square$ 30-35

$\square>35$

Sexo: $\square$ Masculino

$\square$ Feminino

Curso / Unidade:

Semestre cursando: 
Treatment Group 1 (culturally similar + favorable economic gains)

"uma possível parceria comercial existe com um país falante de uma língua parecida com o Português, que partilha os nossos valores sociais e práticas e crenças religiosas, e o Brasil teria vantagens econômicas relativamente elevadas ao firmarem um acordo".

Treatment Group 2 (culturally similar + unfavorable economic gains)

"uma possível parceria comercial existe com um país falante de uma língua parecida com o Português, que partilha os nossos valores sociais e práticas e crenças religiosas, e o Brasil teria vantagens econômicas relativamente baixas ao firmarem um acordo."

Treatment Group 3 (culturally dissimilar + favorable economic gains) "uma possível parceria comercial existe com um país falante de uma língua não parecida com o Português, que não partilha os nossos valores sociais e práticas e crenças religiosas, e o Brasil teria vantagens econômicas relativamente elevadas ao firmarem um acordo.”

Treatment Group 4 (culturally dissimilar + unfavorable economic gains) "uma possível parceria comercial existe com um país falante de uma língua não parecida com o Português, que não partilha os nossos valores sociais e práticas e crenças religiosas, e o Brasil teria vantagens econômicas relativamente baixas ao firmarem um acordo."

\section{Control Group (no cultural or economic gains information)}

"uma possível parceria comercial existe com um país cuja identidade não foi divulgada e para qual os retornos economicos não foram definidos." 
APPENDIX C $_{(1)} \quad-\quad$ Multinomial Logistic Regressions - MODEL 1 (null)

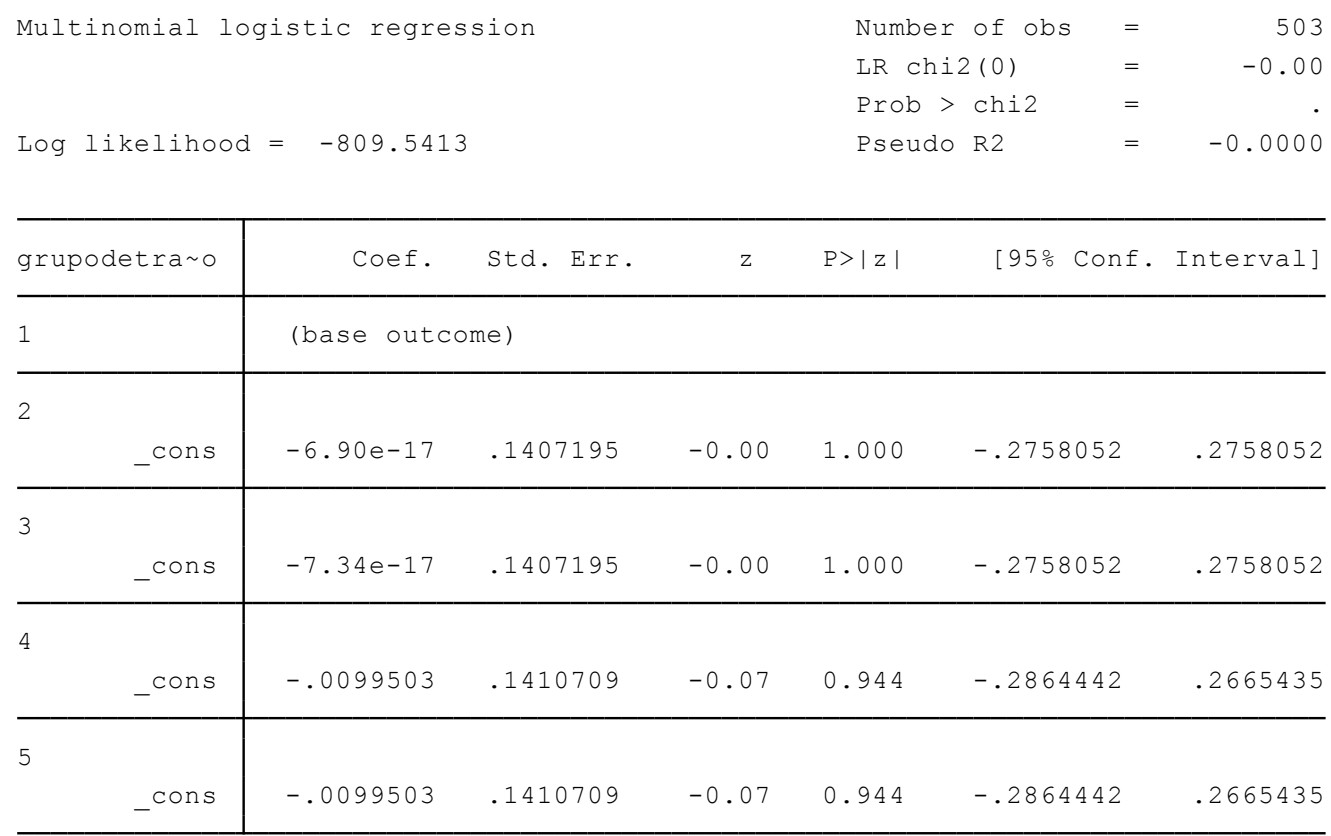

Irtest M1 M2

Likelihood-ratio test

$\operatorname{LR} \operatorname{chi} 2(40)=25.26$

(Assumption: M1 nested in M2)

Prob $>$ chi2 $=0.9665$ 


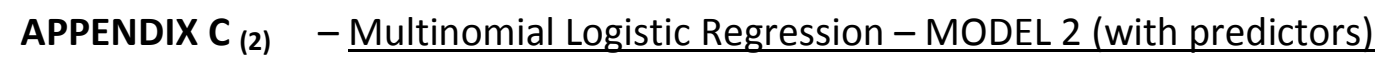

\begin{tabular}{|c|c|c|c|c|c|c|c|}
\hline \multicolumn{4}{|c|}{ Multinomial logistic regression } & \multicolumn{2}{|c|}{ Number of obs } & $=$ & 503 \\
\hline \multirow{3}{*}{\multicolumn{4}{|c|}{ Log likelihood $=-796.91047$}} & \multirow{2}{*}{\multicolumn{2}{|c|}{$\begin{array}{l}\text { LR chi2 }(40) \\
\text { Prob > chi2 }\end{array}$}} & $=$ & 25.26 \\
\hline & & & & & & $=$ & 0.9665 \\
\hline & & & & \multicolumn{2}{|c|}{ Pseudo R2 } & $=$ & 0.0156 \\
\hline grupodetrata o & Coef. & Std. Err. & z & $P>|z|$ & {$[95 \%$} & $\operatorname{con} f$. & Interval] \\
\hline 1 & \multicolumn{3}{|c|}{ (base outcome) } & & & & \\
\hline \multicolumn{8}{|l|}{2} \\
\hline periodofstudy & .0295533 & .1090814 & 0.27 & 0.786 & 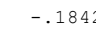 & 2423 & .2433489 \\
\hline semestre & -.0512059 & .0687772 & -0.74 & 0.457 & $-.186 \mathrm{c}$ & 50067 & .083595 \\
\hline faculdade & .0029241 & .076292 & 0.04 & 0.969 & -.146 & 6054 & .1524537 \\
\hline sexo & .0322327 & .3057837 & 0.11 & 0.916 & $-.567 \mathrm{C}$ & 0922 & .6315577 \\
\hline idade & .1064324 & .1875661 & 0.57 & 0.570 & -.261 & 1905 & .4740552 \\
\hline religio & .0179774 & .0545917 & 0.33 & 0.742 & 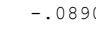 & 0203 & .1249751 \\
\hline renda & .2100419 & .183649 & 1.14 & 0.253 & -.1499 & 9036 & .5699874 \\
\hline conservadorism & .0500242 & .1893471 & 0.26 & 0.792 & $-.321 \mathrm{C}$ & .0893 & .4211376 \\
\hline livedabroad & -.2044127 & .5345716 & -0.38 & 0.702 & -1.252 & 2154 & .8433284 \\
\hline evertravelled & .0423085 & .3213364 & 0.13 & 0.895 & -.587 & 4992 & .6721162 \\
\hline _cons & -.7796661 & .9543086 & -0.82 & 0.414 & $-2.65 c$ & 50077 & 1.090744 \\
\hline \multicolumn{8}{|l|}{3} \\
\hline periodofstudy & .0794123 & .1091427 & 0.73 & 0.467 & -.1345 & 15036 & .2933281 \\
\hline semestre & -.0294549 & .0685558 & -0.43 & 0.667 & -.1638 & 8218 & .1049119 \\
\hline faculdade & .0128279 & .0756837 & 0.17 & 0.865 & $-.1355^{\circ}$ & 5093 & .1611652 \\
\hline sexo & .1542183 & .3046681 & 0.51 & 0.613 & -.4425 & 9202 & .7513567 \\
\hline idade & .0401478 & .1906901 & 0.21 & 0.833 & -.3335 & 5979 & .4138934 \\
\hline religio & .0528257 & .0510657 & 1.03 & 0.301 & -.0472 & 2611 & .1529126 \\
\hline renda & .1942871 & .1837049 & 1.06 & 0.290 & $-.165^{\circ}$ & 7678 & .5543421 \\
\hline conservadorism & .1335099 & .1921381 & 0.69 & 0.487 & $-.2436 \mathrm{Cl}$ & 0739 & .5100937 \\
\hline livedabroad & .415759 & .4987719 & 0.83 & 0.405 & -.56 & 1816 & 1.393334 \\
\hline evertravelled & -.2738203 & .3257223 & -0.84 & 0.401 & $-.912 z$ & 2244 & .3645837 \\
\hline _cons & -1.239722 & .9672813 & -1.28 & 0.200 & -3.135 & 5558 & .6561146 \\
\hline \multicolumn{8}{|l|}{4} \\
\hline periodofstudy & .1191822 & .1119688 & 1.06 & 0.287 & -.1002 & 2726 & .338637 \\
\hline semestre & -.0986413 & .0708347 & -1.39 & 0.164 & -.237 & 4747 & .0401922 \\
\hline faculdade & -.0018096 & .0766475 & -0.02 & 0.981 & $-.152 C$ & 0359 & .1484167 \\
\hline sexo & .272078 & .3121588 & 0.87 & 0.383 & -.339 & 7419 & .8838979 \\
\hline idade & .2927676 & .1807056 & 1.62 & 0.105 & -.061 & 4089 & .6469441 \\
\hline religio & .0246902 & .0544551 & 0.45 & 0.650 & $-.082 C$ & 0398 & .1314201 \\
\hline renda & .0843996 & .1818095 & 0.46 & 0.642 & $-.271 \mathrm{~S}$ & 9405 & .4407396 \\
\hline conservadorism & .0037827 & .1874346 & 0.02 & 0.984 & -.363 & 5822 & .3711477 \\
\hline livedabroad & -.7348379 & .573972 & -1.28 & 0.200 & -1.85 & 98002 & .3901265 \\
\hline evertravelled & .6110765 & .3242046 & 1.88 & 0.059 & -.0243 & 3528 & 1.246506 \\
\hline _cons & -1.284713 & .9545218 & -1.35 & 0.178 & -3.15 & 5541 & .5861159 \\
\hline \multicolumn{8}{|l|}{5} \\
\hline periodofstudy & .1162749 & .1106592 & 1.05 & 0.293 & -.100 & 6131 & .333163 \\
\hline semestre & -.0536113 & .0681828 & -0.79 & 0.432 & -.1872 & 2471 & .0800246 \\
\hline faculdade & .0321166 & .0758656 & 0.42 & 0.672 & -.116 & 5773 & .1808105 \\
\hline sexo & .2402251 & .3104631 & 0.77 & 0.439 & -.3682 & 2713 & .8487215 \\
\hline idade & .2491416 & .180401 & 1.38 & 0.167 & -.1044 & 14378 & .602721 \\
\hline religio & .0382441 & .0521746 & 0.73 & 0.464 & $-.064 c \mathrm{C}$ & 10163 & .1405044 \\
\hline renda & .3371262 & .1875655 & 1.80 & 0.072 & -.030 & 4954 & .7047478 \\
\hline conservadorism & -.0803512 & .186078 & -0.43 & 0.666 & $-.445 c$ & 0574 & .284355 \\
\hline livedabroad & .1227576 & .5080667 & 0.24 & 0.809 & $-.873 \mathrm{C} \quad \mathrm{b}$ & 30348 & 1.11855 \\
\hline evertravelled & -.0402478 & .3257587 & -0.12 & 0.902 & -.678 & 7232 & .5982275 \\
\hline _cons & -1.422271 & .9565345 & -1.49 & 0.137 & -3.29 & 7044 & .4525023 \\
\hline
\end{tabular}

\section{APPENDIX D - $\quad$ Likelihood Ratio Test}

Irtest M1 M2

Likelihood-ratio test

$\operatorname{LR} \operatorname{chi} 2(40)=25.26$

(Assumption: M1 nested in M2)

Prob $>$ chi2 $=0.9665$ 
APPENDIX E - $\quad$ Descriptive Statistics of Background Covariates
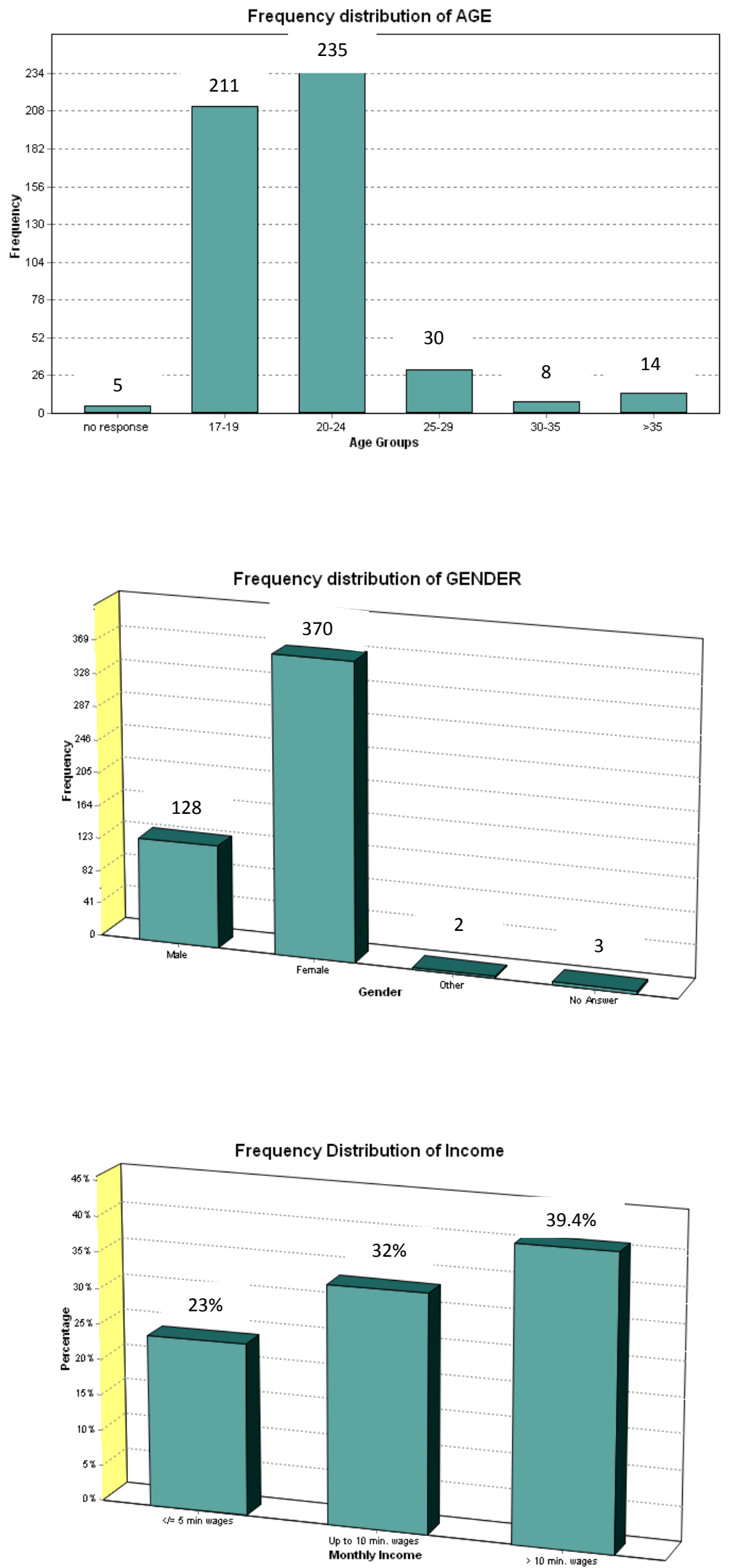

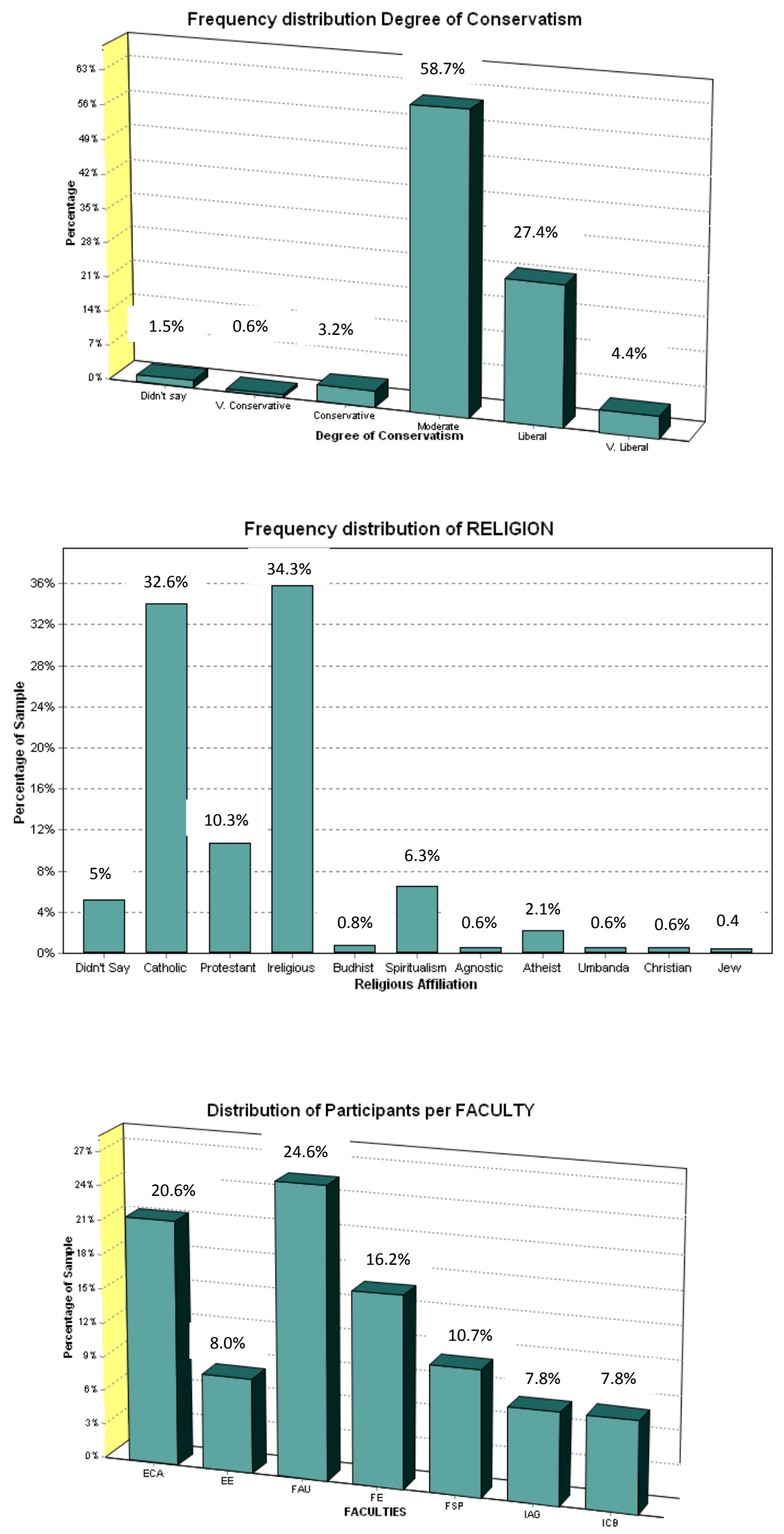


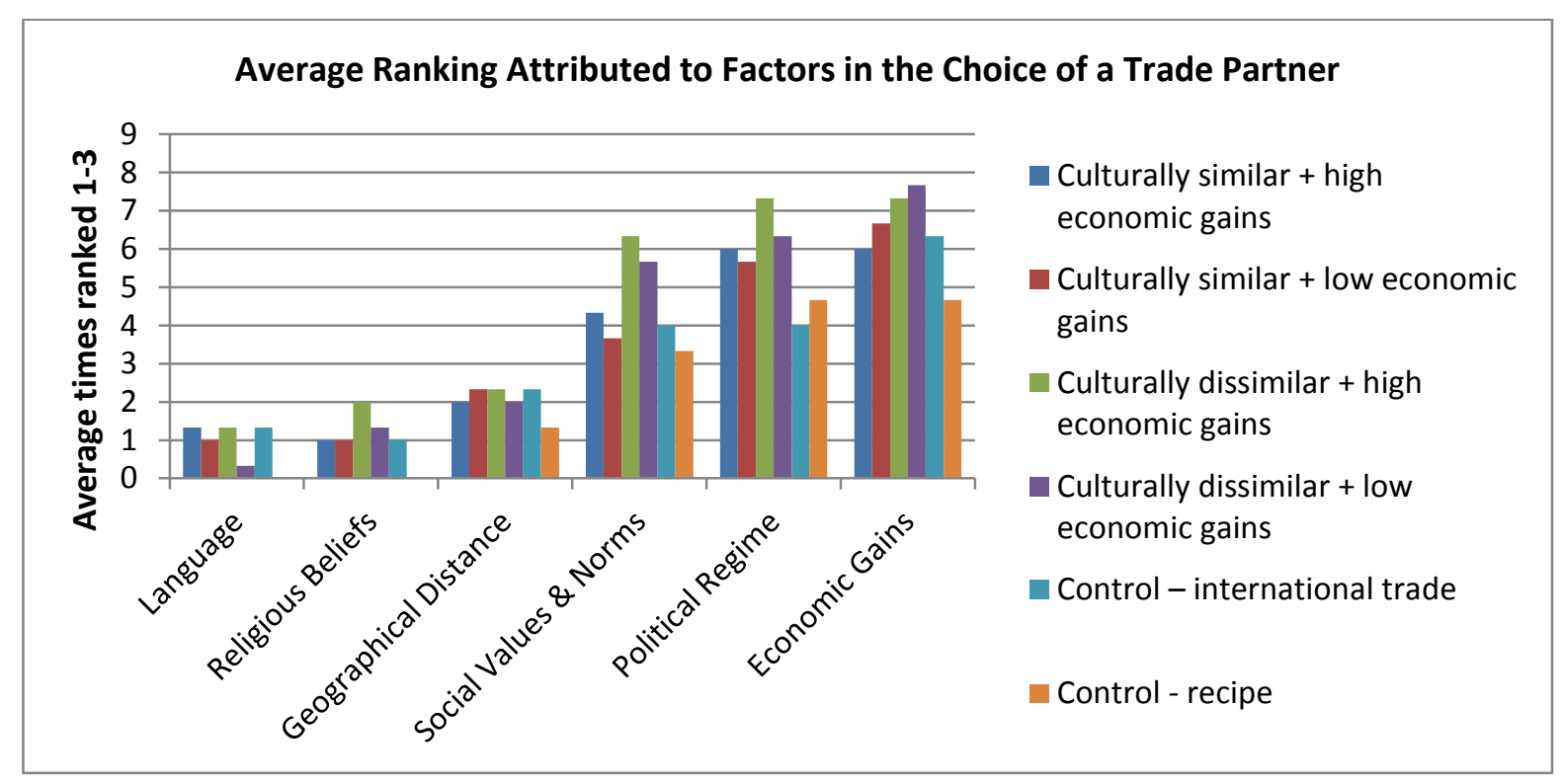


